\title{
əSuper Residual Circulation: A New Perspective on Ocean Vertical Heat Transport
}

\author{
AbHisheK SAVITA, ${ }^{\mathrm{a}, \mathrm{b}, \mathrm{c}}$ JAN D. ZiKa, ${ }^{\mathrm{d}}$ CATIA M. Domingues, ${ }^{\mathrm{a}, \mathrm{c}, \mathrm{e}}$ SimOn J. MARSLAND, ${ }^{\mathrm{a}, \mathrm{b}, \mathrm{c}}$ \\ Gwyn Dafydd Evans, ${ }^{\mathrm{e}}$ Fabio Boeira Dias, ${ }^{\mathrm{a}, \mathrm{b}, \mathrm{c}, \mathrm{f}}$ Ryan M. Holmes, ${ }^{\mathrm{c}, \mathrm{d}, \mathrm{g}}$ AND ANDREW MCC. HogG ${ }^{\mathrm{c}, \mathrm{h}}$ \\ ${ }^{a}$ Institute for Marine and Antarctic Studies, University of Tasmania, Hobart, Tasmania, Australia \\ ${ }^{\mathrm{b}}$ Oceans and Atmosphere, Commonwealth Scientific and Industrial Research Organisation, Aspendale, Victoria, Australia \\ ${ }^{\mathrm{c}}$ Centre of Excellence for Climate Extremes, Australian Research Council, Sydney, New South Wales, Australia \\ ${ }^{\mathrm{d}}$ School of Mathematics and Statistics, University of New South Wales, Sydney, New South Wales, Australia \\ ${ }^{\mathrm{e}}$ National Oceanography Centre, Southampton, United Kingdom \\ ${ }^{\mathrm{f}}$ Institute for Atmospheric and Earth System Research, University of Helsinki, Helsinki, Finland \\ ${ }^{\mathrm{g}}$ Climate Change Research Centre, University of New South Wales, Sydney, Australia \\ ${ }^{\mathrm{h}}$ Research School of Earth Sciences, Australian National University, Canberra, Australian Capital Territory, Australia
}

(Manuscript received 14 January 2021, in final form 6 May 2021)

\begin{abstract}
Ocean circulation and mixing regulate Earth's climate by moving heat vertically within the ocean. We present a new formalism to diagnose the role of ocean circulation and diabatic processes in setting vertical heat transport in ocean models. In this formalism we use temperature tendencies, rather than explicit vertical velocities, to diagnose circulation. Using quasi-steady-state simulations from the Australian Community Climate and Earth-System Simulator Ocean Model (ACCESS-OM2), we diagnose a diathermal overturning circulation in temperature-depth space. Furthermore, projection of tendencies due to diabatic processes onto this coordinate permits us to represent these as apparent overturning circulations. Our framework permits us to extend the concept of "Super Residual Transport," which combines mean and eddy advection terms with subgridscale isopycnal mixing due to mesoscale eddies but excludes small-scale threedimensional turbulent mixing effect, to construct a new overturning circulation-the "Super Residual Circulation" (SRC). We find that in the coarse-resolution version of ACCESS-OM2 (nominally $1^{\circ}$ horizontal resolution) the SRC is dominated by an $\sim 11-\mathrm{Sv}\left(1 \mathrm{~Sv} \equiv 10^{6} \mathrm{~m}^{3} \mathrm{~s}^{-1}\right)$ circulation that transports heat upward. The SRC's upward heat transport is $\sim 2$ times as large in a finer-horizontal-resolution $\left(0.1^{\circ}\right)$ version of ACCESS, suggesting that a differing balance of super-residual and parameterized small-scale processes may emerge as eddies are resolved. Our analysis adds new insight into superresidual processes, because the SRC elucidates the pathways in temperature and depth space along which water mass transformation occurs.
\end{abstract}

KEYWORDS: Advection; Lagrangian circulation/transport; Mesoscale processes; Mixing; Ocean circulation; Vertical motion

\section{Introduction}

The ocean plays a crucial role in regulating Earth's climate by absorbing much of the anomalous heat in the climate system due to anthropogenic greenhouse gases and redistributing it geographically and vertically. The global ocean has accumulated approximately $90 \%$ of the additional human-induced heat since 1971 (Rhein et al. 2013; von Schuckmann et al. 2020), mitigating atmospheric surface warming (Raper et al. 2002; Otto et al. 2013), and causing global mean sea level to rise due to thermal expansion of its volume with a warming ocean (Church et al. 2013; WCRP Global Sea Level Budget Group 2018).

Climate models evaluated as part of phase 5 the World Climate Research Programme's Coupled Model Intercomparison Project (CMIP5) have a large spread in their future projections of ocean heat content change and sea level rise

\footnotetext{
D Denotes content that is immediately available upon publication as open access.
}

Corresponding author: Abhishek Savita, abhishek.abhisheksavita@ utas.edu.au
(Church et al. 2013). Kuhlbrodt and Gregory (2012) investigated this spread in CMIP5 and CMIP3 models and found that it arises as a result of differences in the model's ocean heat uptake and vertical heat transport processes. To understand the CMIP5 spread, it is important to understand the physical mechanisms that transport heat vertically in the ocean component of climate models. The only sources of heat in the ocean interior are from geothermal heating and dissipation of kinetic energy, both of which are so small that they are typically neglected in climate models (including the model discussed here). In the long-term mean and in the absence of perturbations to the climate system (e.g., due to anthropogenic forcing), the total horizontally integrated vertical heat transport is close to zero. However, this small total is the result of a sum of large and competing contributions to the horizontally integrated vertical heat transport from different processes ranging from the large-scale circulation to small-scale turbulent mixing.

Stommel and Arons (1960) and Munk (1966) anticipated that ocean heat can be transported downward by small-scale mixing and upward by the overturning circulation, known as the classical advective-diffusive balance. A circulation that transports heat upward (i.e., involving warm water rising and cold water sinking) acts to stratify and therefore stabilize the water column and is referred to as "thermally direct." 


\section{Thermally Direct}
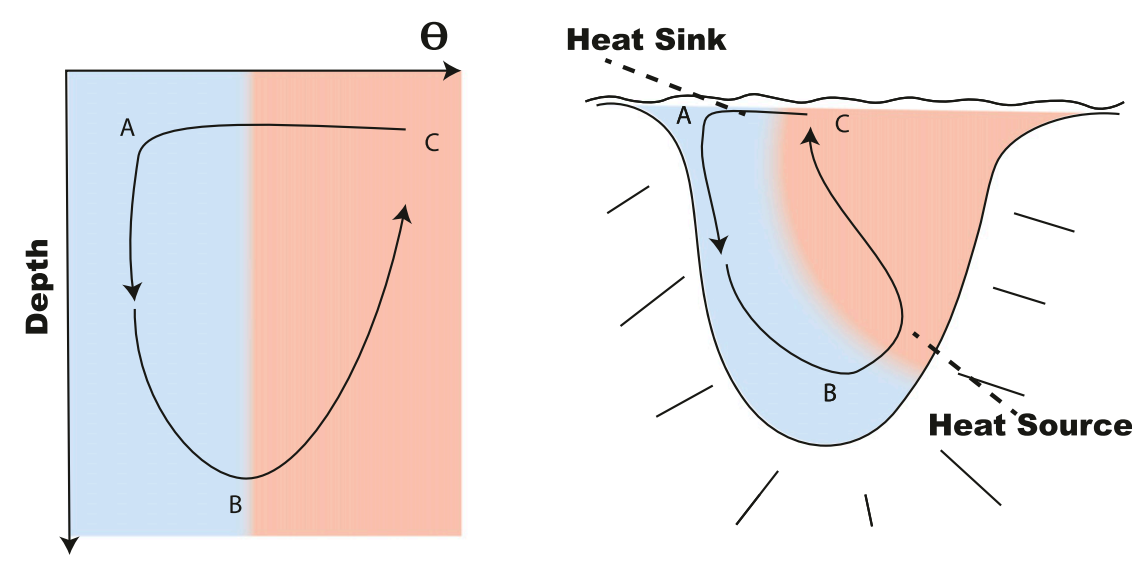

Thermally Indirect
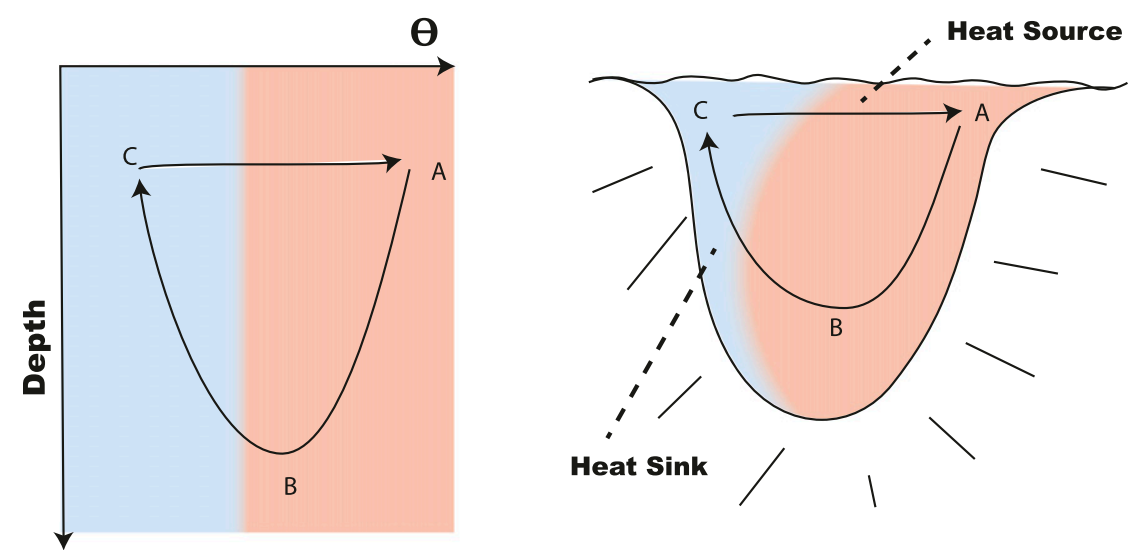

FIG. 1. Schematics describing (top) a thermally direct circulation and (bottom) a thermally indirect circulation. The thermally direct circulation is anticlockwise in (left) temperature-vs-depth coordinates $(T-Z)$ and transports relatively cold water downward and warm water upward, helping to stratify the water column. The thermally indirect cell, which is clockwise in $T-Z$, transports warmer water downward and colder water upward, acting to destratify the water column. These circulations are also shown in (right) geographical coordinates (i.e., latitude vs depth). Typically, the dominant sink of heat is due to a divergence and the dominant source of heat is due to a convergence of diffusive heat fluxes. A thermally direct cell can be driven by thermal forcing with a deep heat source and shallow heat sink supplying available potential energy whereas a thermally indirect cell requires either mechanical (e.g., wind) or haline forcing to counteract the available potential energy being removed by a deep heat sink and a shallow heat source. Note that the blue color shows cold water and the red color shows warm water.

Likewise, a circulation that transports heat downward (i.e., involving cold water rising and warm water sinking) acts to destabilize the water column and is referred to as "thermally indirect" and its schematic is shown in Fig. 1. Several studies based on coupled and ocean general circulation models (OGCMs), however, revealed that heat can also be transported downward in the global ocean by the circulation (resolved advection) and upward by mixing processes (Gregory 2000; Gnanadesikan et al. 2005; Wolfe et al. 2008; Hieronymus and Nycander 2013; Exarchou et al. 2015; Griffies et al. 2015). It has been suggested that overall, the ocean circulation in the upper $2000 \mathrm{~m}$ is not thermally direct (Gregory 2000; Gnanadesikan et al. 2005). Some studies have also investigated the role of the residual transport, defined as the sum of the resolved and parameterized advection (Kuhlbrodt et al. 2015; Zika et al. 2015) and these studies found that overall this transports heat downward (Griffies et al. 2015; Kuhlbrodt et al. 2015).

More recently, Dias et al. (2020a,b) described the role of individual physical processes in vertical ocean heat (and salt) transport as well as the role of the "Super Residual Transport" (SRT) in quasi-steady state and under an idealized anthropogenic climate change scenario, respectively. The SRT was first 
defined by Kuhlbrodt et al. (2015) as the sum of the heat transport due to resolved advection, subgridscale advection, and subgridscale mixing due to mesoscale eddies. Dias et al. (2020a) proposed that the SRT regime in the ocean interior could be reinterpreted as the advective part of the classical advective-diffusive balance. In this SRT perspective, the classical balance has a major role in vertical heat transport but deviates from the original theory with respect to the nonuniform distribution of small-scale mixing, in agreement with more recent theories (e.g., Waterhouse et al. 2014; De Lavergne et al. 2016). Moreover, the SRT allows models with different grid resolutions and physical process parameterizations (i.e., whether processes are resolved or parameterized) to be compared in a consistent framework and can be applied to calibrate simple climate models used in policymaking (e.g., Huber et al. 2015).

However, none of the above process studies analyzed the role of various physical processes in vertical ocean heat transport in tracer versus depth coordinates. Nurser and Lee (2004) and Nycander et al. (2007) were the first to project the ocean circulation into density versus depth coordinates. This framework has the advantage of formally describing how the ocean vertically redistributes buoyancy, and so indicates the energetic drivers of the flow. Nycander et al. (2007) found two major circulation cells: a thermally direct cell (transporting buoyancy upward) at high densities and a thermally indirect cell (transporting buoyancy downward and therefore requiring a source of mechanical energy) at lower densities. Later studies, such as Saenko (2009), found that in some models, when the Eulerian and subgridscale vertical velocities are combined, the thermally indirect cell vanishes since the thermally direct eddy circulation is strong enough to counter the thermally indirect circulation.

Zika et al. (2013a) reported similar circulation cells those discovered by Nycander et al. (2007). By reprojecting the thermally direct and thermally indirect cells onto their geographical locations, they found that the coldest thermally direct cell $\left(<2^{\circ} \mathrm{C}\right)$ was associated with Antarctic Bottom Water (AABW), while the warmer thermally indirect cell (from $2^{\circ}$ to $18^{\circ} \mathrm{C}$ ) was linked with the interhemispheric overturning circulation. Furthermore, a warmer thermally direct cell was confined to the upper ocean (from $18^{\circ}$ to $25^{\circ} \mathrm{C}$ ), which was linked to the subtropical gyres and tropical circulation.

In subsequent work, Zika et al. (2015) confirmed that the eddy-induced thermally direct circulation does not completely counter the thermally indirect circulation in a number of models, indicating that the residual circulation may still have a component that transports heat downward. Based on a simulation with the Community Climate System Model, version 4 (CCSM4), they also found that the downward vertical heat transport by the thermally indirect part of the circulation together with vertical mixing was balanced by a combination of upward heat transport by the thermally direct components of the circulation, and also by nonadvective process such as isopycnal mixing that tend to cool the deep ocean (Kuhlbrodt et al. 2015).

Previous studies have elucidated the role of physical processes and individual components of the ocean circulation in transporting heat vertically, but challenges remain in relating different components of the ocean circulation to specific kinematic (e.g., wind driven) and thermodynamic (e.g., buoyancy driven) processes. That is, individual components of the ocean circulation are mechanically driven, buoyancy driven, or both. In this study, we advance the understanding of the mechanisms of vertical heat transport by precisely relating ocean circulation in temperature versus depth coordinates to individual kinematic and thermodynamic processes that flux heat across temperature surfaces (mixing and surface heat and mass fluxes, Holmes et al. 2019a), in quasi-steady state simulations from the $1^{\circ}$ Australian Community Climate and EarthSystem Simulator Ocean Model (ACCESS-OM2). Further, we extend the SRT concept by projecting it onto temperaturedepth coordinates, resulting in a "Super Residual Circulation" (SRC). This approach combines an analysis of vertical ocean heat transport (Dias et al. 2020a) with that of diathermal ocean heat transport (Holmes et al. 2019a) in a single framework. In this study we define a "diathermal" circulation by summing the residual circulation with the local tendency term as is discussed in section 3c.

In section 2 we describe the ACCESS-OM2 model configurations used in this study. In section 3 we explain how we use the heat budget terms in temperature-depth space to understand the ocean circulation and its associated vertical heat transport, including the definition of the residual, diathermal, and SRT circulation into those coordinates. In section 4 we first present our results on the residual and diathermal circulations, followed by the kinematic and thermodynamic representations of the diathermal circulation and their balance in individual circulation cells. We then investigate the driving mechanisms of the SRC and each of its individual cells. All of these results are based on the coarse-resolution version of ACCESS-OM2. Last, the SRC results are compared between coarse, eddypermitting and eddy-rich ACCESS-OM2 configurations. Discussion and conclusions are found in section 5.

\section{Model description}

Our primary analyses are based on the Australian Community Climate and Earth System Simulator Ocean Model, version 2, with $1^{\circ}$ horizontal resolution (Dias et al. 2020a; Kiss et al. 2020). ACCESS-OM2 is a global model with coupled ocean and sea ice components and prescribed atmospheric forcing. Its ocean component is the Modular Ocean Model, version 5.1 (MOM5; Griffies 2012), from the National Oceanic and Atmospheric Administration Geophysical Fluid Dynamics Laboratory (https://mom-ocean.github.io). The sea ice component is the Los Alamos sea ice model, version 5.1.2 (CICE5; Hunke et al.2015). Coupling of the ocean and sea ice components is achieved using the model coupling toolkit from CERFACS and CNRS, via the Ocean Atmospheric Sea Ice Soil, version 3 (OASIS3-MCT; Valcke 2006).

ACCESS-OM2 solves the primitive equations under the hydrostatic and Boussinesq approximations with a free surface and horizontal spatial discretization on an Arakawa B-grid (Arakawa and Lamb 1977; Griffies and Greatbatch 2012). Following Bi et al. (2013), the vertical grid comprises 50 vertical levels, with thickness increasing from $10 \mathrm{~m}$ at the surface to $333 \mathrm{~m}$ at a depth of $6000 \mathrm{~m}$. The horizontal resolution is 
nominally $1^{\circ}$, with a meridional resolution of $1 / 3^{\circ}$ in the equatorial band, a cosine-dependent (Mercator) meridional resolution in the Southern Ocean, and a tripolar grid in the Arctic (Murray 1996). The prognostic temperature variable is Conservative Temperature-hereinafter temperature $(\Theta)$ - using a pre-TEOS-10 equation of state configuration (Jackett et al. 2006; http://www.teos-10.org/preteos10_software/).

The impacts of mesoscale eddies in ACCESS-OM2 are parameterized using explicit neutral tracer diffusion (Solomon 1971; Redi 1982) and the advective transport parameterization of Gent and McWilliams (1990) and Gent et al. (1995). The latter is implemented in ACCESS-OM2 as a skew diffusion according to Griffies (1998) and Ferrari et al. (2010). The $K$-profile parameterization (KPP) from Large et al. (1994) is used for vertical diffusion of tracers and momentum in the upper ocean. The restratification effect of submesoscale eddies in the mixed layer is parameterized as in Fox-Kemper et al. (2011), implemented again using skew diffusion.

Our ACCESS-OM2 simulation was initialized from rest with temperature and salinity from the World Ocean Atlas 2013 (WOA13; Locarnini et al. 2013; Zweng et al. 2013) and run for 1020 years. Surface forcing is from version 1.3 of the JRA-55do (Tsujino et al. 2018) dataset for forcing ocean/sea ice simulations, derived from the Japanese-55-year atmospheric Reanalysis (JRA-55; Kobayashi et al. 2015). In particular, we use repeat year forcing from 1 May 1984 through 30 April 1985 (RYF8485; Stewart et al. 2020). The last 20 years of the spinup were then used for our analyses (section 4). More details on the model configuration, on the experimental design and quasisteady state simulations are found in Dias et al. (2020a).

To complement analysis of the main ACCESS-OM2 simulation, which was forced with 1984-85 forcing (Dias et al. 2020a), in section 4f we analyze a hierarchy of simulations from $1^{\circ}$ to $0.1^{\circ}$ resolution, all of which were forced with repeat year forcing 1990-91. These simulations used updated version of the $1^{\circ}$ (ACCESS-OM2-1), $0.25^{\circ}$ (ACCESS-OM2-025, "eddypermitting"'), and $0.1^{\circ}$ (ACCESS-OM2-01, “eddy-rich”) configurations described in Kiss et al. (2020).

The ACCESS-OM2-1 and ACCESS-OM2-025 configurations have 50 vertical levels and uses the vertical grid scheme of Stewart et al. (2017) that has refined vertical resolution in the upper ocean, as compared with the main ACCESS-OM2 configuration discussed above, in order to better resolve baroclinic modes on the continental shelves (from $2.3 \mathrm{~m}$ at the surface to $219 \mathrm{~m}$ in the abyssal ocean). ACCESS-OM2-01 has an even finer vertical resolution [75 vertical levels following the Stewart et al. (2017) scheme, from $1.1 \mathrm{~m}$ at the surface to $200 \mathrm{~m}$ in the abyssal ocean] than the other configurations. As ACCESSOM2-025 only partially resolves eddies, it also includes the Gent and McWilliams (1990) and Redi (1982) parameterizations for the mixing effects of subgridscale mesoscale eddies but with smaller mixing coefficients than ACCESS-OM2-1. More details of the mixing coefficient used in these configurations are available in Table 1. As ACCESS-OM2-01 is an eddy rich model, and hence there is no parameterization for mesoscale eddies.

All three configurations (ACCESS-OM2-1, ACCESS-OM2025, and ACCESS-OM2-01) were initialized with the same monthly climatologies of temperature and salinity from
WOA13. Due to computational expense the length of the model spinup reduces with increasing horizontal resolution. We used the 1990-91 repeat year forcing for these simulations to be consistent across the resolutions. Note that, these three simulations are only discussed in section $4 \mathrm{f}$, the remainder of our analysis focuses exclusively on the main $1^{\circ}$ ACCESSOM2 simulation used in Dias et al. (2020a).

\section{Methods}

Here we describe how we use temperature versus depth coordinates to understand the ocean circulation and its associated vertical heat transport.

\section{a. Heat budget}

A common way to analyze the ocean's temperature budget is to use an Eulerian approach (Gregory 2000; Hieronymus and Nycander 2013; Exarchou et al. 2015; Dias et al. 2020a,b) where

$$
\frac{\partial \Theta}{\partial t}=-\nabla \cdot(\mathbf{u} \Theta)+\nabla \cdot\left(K_{\text {eddy }} \Theta\right)+\nabla \cdot\left(K_{\text {small }} \Theta\right)+\frac{F}{\rho_{0} C_{p}} .
$$

The left-hand side of Eq. (1) is the local temperature tendency. The right-hand side represents the convergence of resolved and parameterized (subgridscale) physical processes and other sources of heat, with units of degrees Celsius per second. Specifically, $\mathbf{u}$ is the $3 \mathrm{D}$ residual velocity, $K_{\text {eddy }}$ is a diffusion tensor representing mesoscale eddy mixing, $K_{\text {small }}$ is a diffusion tensor that encompasses mixing processes typically smaller than mesoscale eddy scales, $F$ comprises the remaining local heat sources such as surface forcing $\left(\mathrm{W} \mathrm{m}^{-3}\right), \rho_{0}$ is a reference density $\left(1035 \mathrm{~kg} \mathrm{~m}^{-3}\right)$, and $C_{p}$ is the heat capacity $\left(\sim 3992 \mathrm{~J} \mathrm{~kg}^{-1} \mathrm{~K}^{-1}\right)$. The terms in Eq. (1) are provided as model diagnostics in ACCESS-OM2 at each grid cell as

$$
\begin{aligned}
-\nabla \cdot(\mathbf{u} \Theta) & =\mathrm{ADV}+\mathrm{MESO}+\mathrm{SUB}, \\
\nabla \cdot\left(K_{\text {eddy }} \Theta\right) & =\mathrm{ISO}, \\
\nabla \cdot\left(K_{\text {small }} \Theta\right) & =\mathrm{DIA}+\mathrm{KPP}+\mathrm{CON}+\mathrm{SIGMA} \_\mathrm{DIFF}, \\
F & =\mathrm{SFC}+\mathrm{SWP}+\mathrm{PME}+\mathrm{RIV}+\mathrm{FRZ} .
\end{aligned}
$$

Here, ADV is mean advection by the velocity resolved by ACCESS-OM2, MESO is mesoscale advection (Gent et al. 1995) implemented as a skew diffusion (Griffies 1998), SUB is restratification in the mixed layer due to submesoscale eddies (Fox-Kemper et al. 2011) also implemented as a skew diffusion, ISO is isoneutral diffusion (Redi 1982; Griffies et al. 1998), DIA is dianeutral diffusion including the background vertical diffusion and diffusion associated with other parameterization schemes including KPP, KPP is the nonlocal component of the $K$-profile parameterization (Large et al. 1994), CON is convection due to buoyancy instability (Klinger et al. 1996) and also includes a contribution from downslope mixing (Snow et al. 2015), SIGMA_DIFF is diffusion along the slope of topography (Beckmann and Döscher 1997), SFC captures the turbulent and radiative surface heat fluxes (where the penetration of shortwave radiation into the interior is treated 
TABLE 1. Configuration and initialization differences across ACCESS-OM2, ACCESS-OM2-1, ACCESS-OM2-025, and ACCESS-OM2-01 experiments.

\begin{tabular}{|c|c|c|c|c|}
\hline ACCESS model & OM2 & OM2-1 & OM2-025 & OM2-01 \\
\hline Horizontal resolution & $1^{\circ}$; not eddy resolving & $1^{\circ}$; not eddy resolving & $\begin{array}{l}0.25^{\circ} \text {; eddy } \\
\text { permitting }\end{array}$ & $0.1^{\circ}$; eddy rich \\
\hline No. vertical grid cells & 50; Adcroft and Campin (2004) & 50; Stewart et al. (2017) & $\begin{array}{l}\text { 50; Stewart } \\
\text { et al. (2017) }\end{array}$ & $\begin{array}{l}75 \text {; Stewart } \\
\text { et al. (2017) }\end{array}$ \\
\hline Spinup length & $1020 \mathrm{yr}$ & $1020 \mathrm{yr}$ & $500 \mathrm{yr}$ & $175 \mathrm{yr}$ \\
\hline $\begin{array}{l}\text { Eddy-induced advection } \\
\text { coef }\left(\mathrm{m}^{2} \mathrm{~s}^{-1}\right)\end{array}$ & $50-600$ & $50-600$ & $1-200$ & Not parameterized \\
\hline $\begin{array}{l}\text { Along-isopycnal neutral } \\
\text { diffusion coef }\left(\mathrm{m}^{2} \mathrm{~s}^{-1}\right)\end{array}$ & 600 & 600 & 200 & Not parameterized \\
\hline Background vertical diffusivity & $\begin{array}{c}1 \times 10^{-6} \mathrm{~m}^{2} \mathrm{~s}^{-1} \text { at the equator } \\
\text { and } 5 \times 10^{-6} \mathrm{~m}^{2} \mathrm{~s}^{-1} \text { pole- } \\
\text { ward of } \pm 20^{\circ}(\text { Jochum } 2009)\end{array}$ & $\begin{array}{l}1 \times 10^{-6} \mathrm{~m}^{2} \mathrm{~s}^{-1} \text { at the equator } \\
\text { and } 5 \times 10^{-6} \mathrm{~m}^{2} \mathrm{~s}^{-1} \text { pole- } \\
\text { ward of } \pm 20^{\circ}(\mathrm{Jochum} 2009)\end{array}$ & 0.0 & $1 \times 10^{-6} \mathrm{~m}^{2} \mathrm{~s}^{-1}$ \\
\hline
\end{tabular}

separately as SWP) (Sweeney et al. 2005), PME and RIV are the heat fluxes associated with the surface volume fluxes due to precipitation minus evaporation and river runoff, respectively, and FRZ denotes the heat flux into the ocean associated with frazil formation (sea ice). All of the diagnostics used in Eq. (1) were output as monthly averages. In this study we use temperature tendency diagnostics that close the heat budget by construction (Dias et al. 2020a,b). This closure is important because offline calculations of the advective vertical heat transport based on vertical velocities multiplied by grid cell interface temperature can be inaccurate (Zika et al. 2015).

\section{b. Residual circulation}

The standard approach to calculate the residual circulation in temperature-depth coordinates is to accumulate the vertical velocity as a function of temperature at constant depth $Z$. That is,

$$
\psi\left(\Theta^{\prime}, Z^{\prime}\right)=\iint_{\Theta<\Theta^{\prime}, Z=Z^{\prime}} w d A
$$

At depth $Z^{\prime}$ and conservative temperature $\Theta^{\prime}, \psi\left(Z^{\prime}, \Theta^{\prime}\right)$ is the total vertical volume transport through the $Z^{\prime}$ depth surface and at temperatures colder than $\Theta^{\prime}$. Here $w$ is the residual vertical velocity. The residual vertical velocity is the sum of the mean and eddy-induced components of the vertical velocity. The latter is the velocity due to parameterizations of mesoscale eddies from Gent and McWilliams (1990) and Gent et al. (1995), along with mixed layer submesoscale eddies from FoxKemper et al. (2011). However, note that these parameterizations are implemented in the model using skew diffusion. The eddy velocity diagnosed here is that which would result in the same tracer evolution if the parameterization were instead implemented advectively (Griffies 1998). Here, $\psi\left(\Theta^{\prime}, Z^{\prime}\right)$ represents the residual circulation in temperature-versus-depth coordinates using residual vertical velocity and does not comprise other subgridscale effects such as eddy diffusion since these are not represented as an advective process (neither in the model nor as a postprocessed diagnostic).

The total heat transport due to the residual circulation is typically computed by integrating $\psi$ in temperature coordinates such that

$$
\begin{aligned}
\text { vertical heat transport }\left(Z=Z^{\prime}\right) & =C_{p} \rho_{0} \iint_{Z=Z^{\prime}} w \Theta d A \\
& =C_{p} \rho_{0} \int \psi\left(Z^{\prime}, \Theta\right) d \Theta
\end{aligned}
$$

To calculate the heat transport due to distinct components of the circulation, we use the method of Ferrari and Ferreira (2011), by integrating the residual circulation over the temperature range associated with a particular closed cell of $\psi$.

A limitation of Eq. (3) arises from the fact that the vertical advective heat transport is not exactly related to the model's average $w$ multiplied by its average $\Theta$ since advection schemes are typically nonlinear and involve various flux limiters and numerical stencils (Domingues et al. 2006). Thus, the vertical heat transport diagnosed from Eqs. (2) and (3) does not correspond exactly to the horizontal and vertical integral of the heat tendency terms in Eq. (1). Also, the time scale on which $w$ and $\Theta$ are saved can affect the diagnosed total heat transport (Zika et al. 2013a, their Fig. A1).

Given that we are considering an incompressible flow, we can exploit the divergence theorem to give the following alternative formulation for $\psi$, here denoted by $\psi^{*}$

$$
\psi^{*}\left(\Theta^{\prime}, Z^{\prime}\right)=-\iint_{Z<Z^{\prime}, \Theta=\Theta^{\prime}} \mathbf{u} \cdot \nabla \Theta /|\nabla \Theta| d A
$$

In Eq. (4) we are integrating the velocity normal to the surface where $\Theta=\Theta^{\prime}$ below the depth $Z^{\prime}$. Since the flow is incompressible the integral in Eq. (4) is exactly opposite to the formulation given by Eq. (3). Note that Eq. (4) does not describe the transport across the $\Theta=\Theta^{\prime}$ temperature surface. It only describes the transport normal to the surface. Equation (4) therefore describes the combination of the inflation of the temperature layer and the amount of fluid crossing the temperature surface bounding it. For an incompressible fluid, this is exactly equal to the amount of water entering the layer across the depth surface (which itself does not move) described by Eq. (3).

It is numerically more convenient to restate Eq. (4) as the derivative of a volume integral rather than an area integral (see section 7.4 of Groeskamp et al. 2019) such that 


$$
\psi^{*}\left(\Theta^{\prime}, Z^{\prime}\right)=-\frac{\partial}{\partial \Theta} \iiint_{Z<Z^{\prime}, \Theta<\Theta^{\prime}} \nabla \cdot(\mathbf{u} \Theta) d V .
$$

Now the term in the integral of Eq. (5), $\nabla \cdot(\mathbf{u} \Theta)$, is the advection term in the heat budget, and therefore this formulation of $\psi^{*}$ can be derived directly from the net advective heat flux convergence. It can then, through Eq. (3), be related to the net advective vertical heat transport.

In the following sections we will show that Eq. (5) furthermore allows us to evaluate the contribution of different heat budget terms to the circulation in temperature versus depth coordinates.

\section{c. Diathermal circulation}

In principle, if the volume below each depth and colder than each temperature is constant in time, then the amount of water crossing a depth surface below a certain temperature is equivalent to the amount of water crossing a temperature surface below a certain depth. That is, $\psi$ represents a "streamfunction," and flow can be thought of as following its streamlines in a mean sense. Therefore, in this steady state case, we can consider the circulation both from the point of view of the vertical transport crossing depth surfaces, $\psi^{*}$ [Eq. (5)—related to kinematic processes] and from the point of view of the transport of water across temperature surfaces (related to thermodynamic processes), which we call the diathermal circulation $\psi^{\text {dia }}$.

The rate at which water crosses an isotherm locally is the velocity normal to the temperature surface plus an effect relating the movement of the isotherm surface itself (Groeskamp et al. 2014). Thus, we can define an accumulated diathermal transport $\psi^{\text {dia }}$ as

$$
\begin{aligned}
\psi^{\text {dia }}\left(\Theta^{\prime}, Z^{\prime}\right) & =-\iint_{Z<Z^{\prime}, \Theta=\Theta^{\prime}}\left[\frac{\partial \Theta}{\partial t}+\nabla \cdot(\mathbf{u} \Theta)\right] /|\nabla \Theta| d A \\
& =-\frac{\partial}{\partial \Theta} \iiint_{Z<Z^{\prime}, \Theta<\Theta^{\prime}} \frac{\partial \Theta}{\partial t}+\nabla \cdot(\mathbf{u} \Theta) d V \\
& =-\frac{\partial}{\partial \Theta} \iiint_{Z<Z^{\prime}, \Theta<\Theta^{\prime}} \frac{\partial \Theta}{\partial t} d V+\psi^{*} .
\end{aligned}
$$

Although $\psi^{\text {dia }}$ represents a volume transport, it is related directly to the Lagrangian temperature tendency, which is given by the sum of the local tendency plus convergence due to advection both resolved and parameterized. We will refer to $\psi^{\text {dia }}$ as the "diathermal circulation." Alternatively, diathermal volume transports can only occur in the presence of diabatic processes (i.e., surface forcing or turbulent mixing) that change the heat content of a given fluid parcel (Holmes et al. 2019a). Thus, $\psi^{\text {dia }}$ can be equivalently expressed in terms of these diabatic processes [using Eq. (1)],

$$
\begin{aligned}
\psi^{\text {dia }}\left(\Theta^{\prime}, Z^{\prime}\right)= & -\frac{\partial}{\partial \Theta} \iiint_{Z<Z^{\prime}, \Theta<\Theta^{\prime}}\left[\nabla \cdot\left(K_{\text {eddy }} \Theta\right)\right. \\
& \left.+\nabla \cdot\left(K_{\text {small }} \Theta\right)+\frac{F}{\rho_{0} C_{p}}\right] d V .
\end{aligned}
$$

Equation (7) defines a measure of the depth-temperature overturning circulation that is traceable only to the Eulerian diabatic temperature tendency terms. This alternative view of the temperature-depth circulation streamfunction is similar to the linkage of circulation in the latitude-temperature plane to diabatic processes discussed by Holmes et al. (2019b). Other advantages of this new formalism include the following:

(i) We can compute the sum of the local heat content change and advective heat flux directly from $\psi^{\text {dia }}$ using Eq. (3) and be guaranteed that the result will be exactly equal and opposite to the heat loss due to diabatic processes (not shown).

(ii) We can evaluate the contribution to the temperature-depth circulation of each term in the heat budget and hence the role of each either kinematic or diabatic process in stabilizing or destabilizing the water column. These diagnostics describe the "equivalent" temperature-depth circulation that would achieve the vertical heat transport given by each term in the budget.

(iii) We can determine different circulations due to the combined effect of different temperature tendency terms relating to different scales of ocean physics.

In section $3 \mathrm{~d}$ we will consider ii, and then in section $3 \mathrm{e}$ we expand on iii and derive a circulation describing superresidual processes: the SRC.

\section{d. Circulation due to individual diabatic processes}

It is routine to represent ocean circulation as having distinct components related to Eulerian mean advection and other contributions to the flow that are represented by distinct velocity vectors (either explicitly in a model or as a diagnostic such as in the case of skew diffusion in ACCESS). The formalism we have presented in the previous sections permits us to present any term in the temperature tendency Eq. (1) as a circulation in temperature-depth space.

For example, the circulation attributable to parameterized mesoscale eddy induced diffusion can be computed via

$$
\text { Eddy diffusion circulation }=\frac{\partial}{\partial \Theta} \iint_{Z<Z^{\prime}, \Theta<\Theta^{\prime}} \nabla \cdot\left(K_{\text {eddy }} \Theta\right) d V \text {. }
$$

It is important to note here that the inferred circulation for eddy diffusion is not the contribution of eddy mixing to the residual or diathermal circulation. Rather it is the circulation that would be required to affect the same vertical heat transport as induced by eddy diffusion. In the case of eddy diffusion, since this term typically induces a large upward heat transport, we expect it to be dominated by a thermally direct circulation. Convection (i.e, $\mathrm{CON}$ ), which restratifies gravitationally unstable water columns, we also expect to be associated with a thermally direct circulation (unless salinity is the dominant driver of the instability). Stratified vertical mixing (i.e., DIA) on the other hand tends to mix heat downward (when the temperature stratification is stable), which we expect to be described by a thermally indirect circulation. In section $4 c$ we show the relevant circulations for a range of parameterized processes in ACCESS. 


\section{e. $S R C$}

The SRT describes the bulk contribution of Eulerian mean advection, mesoscale eddy advection and mesoscale eddy diffusion to vertical heat transport. Here we extend this concept to derive the net contribution of those processes to the circulation in temperature versus depth coordinates. We call this circulation the SRC.

We define $\psi^{\mathrm{SRC}}\left(\Theta^{\prime}, Z^{\prime}\right)$ as in Eq. (6) but drawing all the eddy effects into the integral such that

$$
\psi^{\mathrm{SRC}}\left(\Theta^{\prime}, Z^{\prime}\right)=\frac{\partial}{\partial \Theta} \iiint_{Z<Z^{\prime}, \Theta<\Theta^{\prime}}-\nabla \cdot(\mathbf{u} \Theta)+\nabla \cdot\left(K_{\text {eddy }} \Theta\right) d V
$$

Here $\psi^{\text {SRC }}$ comprises the sum of the ADV, MESO, ISO, and SUB terms of the heat budget (section 3a), so the SRC represents the total advective circulation due to resolved and parameterized eddy processes. By also including the submesoscale advection (SUB) term, which captures the effect of submesoscale instabilities in the mixed layer (Fox-Kemper et al. 2011; Zhang et al. 2019), our SRC slightly deviates from the original SRT definition in terms of mean advection (ADV), eddy advection (MESO), and eddy mixing (ISO) contributions to the vertical heat transport (Kuhlbrodt et al. 2015; Dias et al. 2020a,b). In section 4 we show results of vertical heat transport by SRC with and without SUB. Again, the vertical heat transport achieved by the SRC is calculated using Eq. (3) by integrating $\psi^{\mathrm{SRC}}\left(\Theta^{\prime}, Z^{\prime}\right)$ with respect to temperature.

To summarize, the key motivations for defining $\psi^{\mathrm{SRC}}$ are the following:

1) By combining resolved and parameterized advection with eddy mixing terms we yield an apparent circulation that represents all large and mesoscale circulation processes.

2) Combining all these processes means $\psi^{\text {SRC }}$ from coarseresolution models (where mesoscale processes are parameterized) can be compared with circulations derived from data that capture mesoscale processes directly, for example fine-resolution models.

3) The $\psi^{\mathrm{SRC}}$ represents a circulation whose vertical heat transport, in steady state, is balanced only by small-scale three-dimensional mixing processes as in the classical advective diffusive balance hypothesized by Munk (1966).

\section{f. Numerical implementation of diagnostics}

For all diagnostics that required binning into temperature coordinates this binning was performed offline based on monthlyaveraged tendency and temperature outputs. Specifically, for the computation of $\psi$ [Eq. (2)] vertical velocity components were saved monthly on the model Eulerian grid. These were multiplied by grid cell interface area, binned at constant depth in $0.5^{\circ} \mathrm{C}$ temperature bins using the monthly-averaged Eulerian temperature field and then accumulated with respect to temperature from coldest to warmest. This binning is repeated for each monthly mean fields, then an average is taken over the last 20 years of the simulation.
For the computation of $\psi^{*}$ [Eq. (5)] vertical grid cell thickness weighted advective tendency terms were saved monthly on the model grid, multiplied by grid cell area and then binned at constant depth in $0.5^{\circ} \mathrm{C}$ temperature bins using the monthlyaveraged temperature field and then accumulated with respect to depth from deepest to shallowest. The same approach was also used for all other terms in the temperature budget. To form $\psi^{\mathrm{SRC}}$ [Eq. (9)], for example, appropriate terms were summed together. Again, the binning was performed for each month and then a 20-yr average was taken.

We have repeated our analysis for ACCESS-OM2 with a bin size of $0.1^{\circ} \mathrm{C}$ and found that this does not significantly change our results for the total heat transport. In terms of the finer details of the overturning diagnostics, as the bin size increases some noise is introduced associated with the advective tendency term (not shown). Therefore, we choose a bin size of $0.5^{\circ} \mathrm{C}$ for the rest of the analysis. Although the heat budget is closed at each grid cell, some of our result may be sensitive to the use of offline binning. For example, Holmes et al. (2019a) found that online binning was required to close the heat budget in temperature coordinate sufficiently to accurately diagnose numerical mixing.

\section{Results}

\section{a. Residual and diathermal circulation}

In ACCESS-OM2, the vertical velocity based residual circulation $\psi$ has two thermally direct cells (bottom and surface; blue) and a thermally indirect cell (deep; red) (Fig. 2a), as in Zika et al. (2013a). The thermally direct cells (anticlockwise/blue) transport heat upward and so act to stabilize the ocean's vertical stratification while the thermally indirect cell transports heat downward into the ocean interior (clockwise; red). Zika et al. (2013a) linked the thermally direct cell at temperatures below $3^{\circ} \mathrm{C}$ with Antarctic Bottom Water formation and circulation, and that at temperatures greater than $15^{\circ} \mathrm{C}$ with the shallow tropical and subtropical overturning cells. They associated the thermally indirect cell with the interhemispheric meridional overturning circulation associated with North Atlantic Deep Water. While expected, it is also reassuring to confirm these basic structural features of the ocean's circulation.

The residual circulation derived from advective temperature tendencies $\psi^{*}$ is qualitatively similar to $\psi$ and displays the same thermally direct and indirect cells (Fig. 2b). The sum of the integral of the local tendency and $\psi^{*}$ [Eq. (6)] defines a diathermal circulation $\psi^{\text {dia }}$, shown in Fig $2 \mathrm{c}$, that is also similar.

The total horizontally integrated vertical heat transport computed from $\psi^{*}$ and $\psi$ using Eq. (3) are shown in Fig. 2d. Since $\psi^{*}$ is based on the temperature tendencies, the total vertical heat flux derived from it is the most accurate obtainable, and the only representation that can produce a closed heat budget. It can be seen that $\psi$ underestimates the downward heat transport in the upper $2000 \mathrm{~m}$ and overestimates the upward heat transport in the deep ocean relative to $\psi^{*}$. It is important that vertical heat transport differences between $\psi$ and $\psi^{*}$ are largest at depth $1000 \mathrm{~m}$ (where $\psi$ transports less heat 
(a) Residual Circulation ( $\psi$ : from vertical velocity)

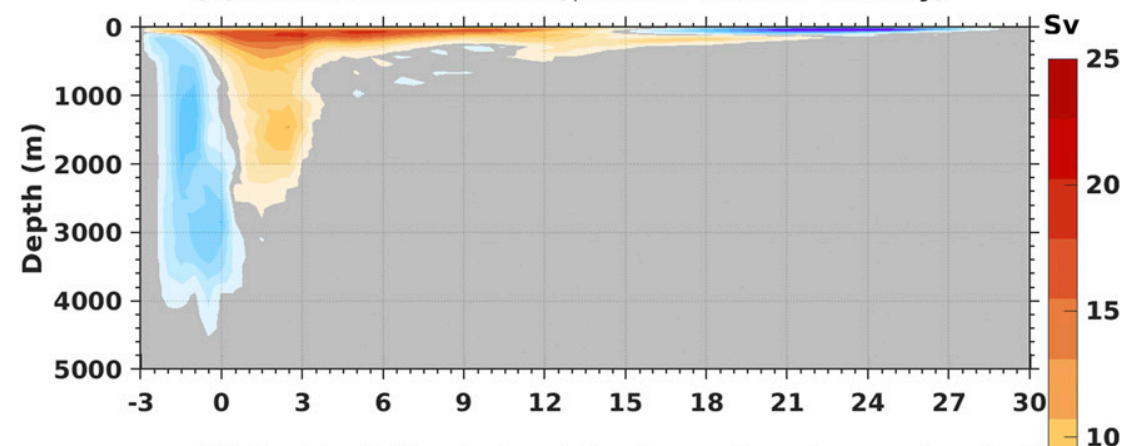

(b) Residual Circulation ( $\psi^{*}$ : from advective tendencies)

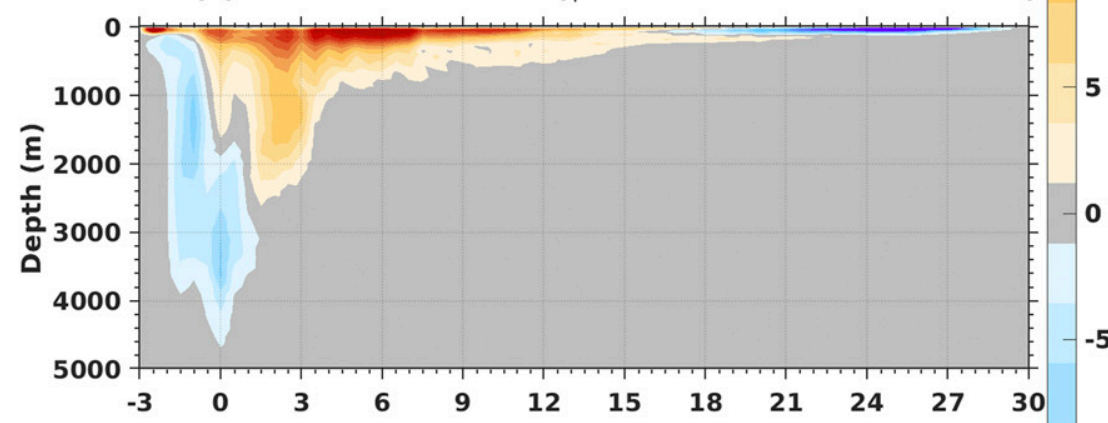

(c) Diathermal Circulation ( $\psi^{\mathrm{dia}}$ )

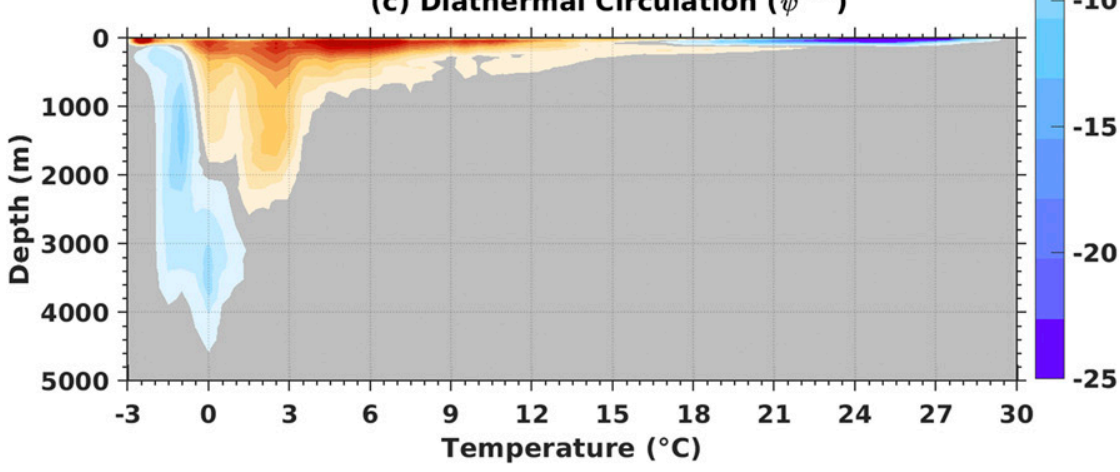

(d) Vertical heat transport

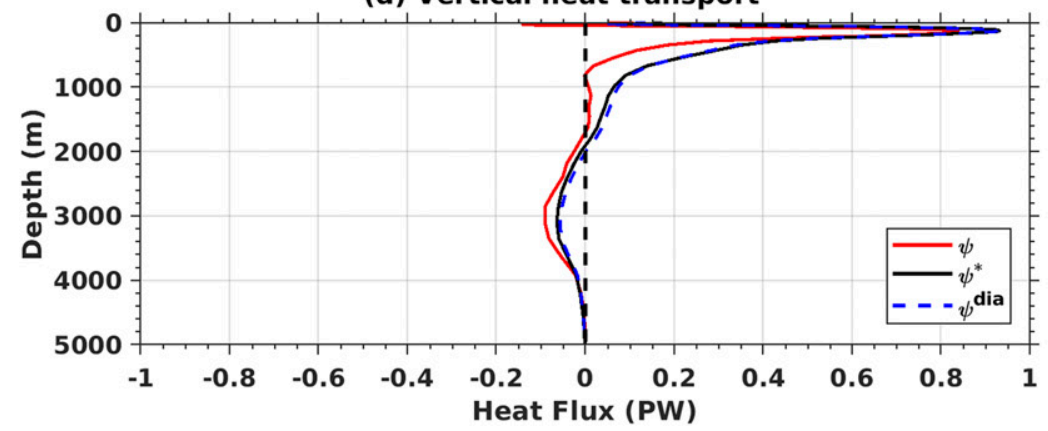

FIG. 2. Overturning circulation $\left(\mathrm{Sv}, \equiv 10^{6} \mathrm{~m}^{3} \mathrm{~s}^{-1}\right)$ in temperature-vs-depth coordinates (a) computed using the residual vertical velocity $\psi$, (b) computed using advective tendencies $\psi^{*}$, and (c) computed using the local time tendency plus advection tendency $\psi^{\text {dia }}$. Positive (red) values show clockwise (thermally indirect) circulation, and negative (blue) cells are anticlockwise (thermally direct). (d) Vertical heat transport (PW, $\equiv 10^{15} \mathrm{~W}$; positive downward) calculated using $\psi$ (red), $\psi^{*}$ (black), and $\psi^{\text {dia }}$ (blue dashed). 
downward than $\left.\psi^{*}\right)$ and also at $3000 \mathrm{~m}(\psi$ transports more heat upward).

We also found that the mismatch between the heat transport described by $\psi$ and $\psi^{*}$ remains similar as temperature resolution of the binning is increased (not shown). This suggests their mismatch relates to a difference between the actual vertical heat flux computed by ACCESS-OM2's advection scheme and a heat flux derived offline from the model's vertical velocity and temperature. The residual circulation $\psi^{*}$ exactly describes the vertical heat transport. We will use tendencies for the remainder of our analysis.

The diathermal circulation $\psi^{\mathrm{dia}}$ is qualitatively similar to $\psi^{*}$ displaying the same thermally direct and indirect cells (indicating that local tendency is relatively weak). Since by construction the heat budget in Eq. (1) is satisfied at each grid cell in ACCESS-OM2, our calculation of $\psi^{\text {dia }}$ is identical regardless of whether we use Eqs. (6) or (7) (Fig. 2c). Also, $\psi^{\text {dia }}$ using Eq. (6) shows the kinematic contribution to $\psi^{\text {dia }}$ whereas Eq. (7) shows the contribution of thermodynamic processes to $\psi^{\text {dia }}$. We therefore investigate the contribution of both kinematic and thermodynamic processes to $\psi^{\mathrm{dia}}$ and the associated heat transport.

\section{b. Diathermal circulation from kinematic terms in the temperature budget}

We compute the contribution of the resolved mean (ADV), parameterized mesoscale (MESO) and parameterized submesoscale (SUB) advection to $\psi^{\mathrm{dia}}$. The contribution of mean advection is dominated by a thermally indirect circulation, transporting warmer water downward and colder water upward (Fig. 3a). The contribution of parameterized mesoscale advection displays a single thermally direct cell with a tendency to transport warm water upward and relatively cold water downward (Fig. 3b). The parameterized submesoscale advection contribution is also thermally direct but is confined to the ocean shallower than $700 \mathrm{~m}$ (Fig. 3c), as submesoscale advection is a parameterized mixed layer process (Fox-Kemper et al. 2011).

The thermally direct nature of the parameterized eddy advection is expected since such parameterizations are designed to lower the potential energy of the ocean (Gent et al. 1995; Fox-Kemper et al. 2011) and temperature dominates density variations in most regions of the interior ocean. There is a large cancelation between the thermally indirect mean and the thermally direct eddy advective circulations. This cancelation has been observed in density-depth coordinates in both coarseresolution (Saenko 2009, their Fig. 10) and eddy-permitting simulations (Zika et al. 2013b; Hogg et al. 2017), and is a notable feature of the Southern Ocean.

The final term that we have considered in the calculation of $\psi^{\text {dia }}$ from Eq. (6) is the Eulerian local tendency term $\partial \Theta / \partial t$. If the simulations were in a perfect steady state this term would be zero. Indeed, over our averaging window the local tendency term is close to but not perfectly zero (Fig. 3d). This small local tendency term is likely due to underlying residual drift in the model's water masses away from the initial condition and due to internal variability in the model (Dias et al. 2020a, their Fig. 1).

\section{c. Circulation related to thermodynamic terms in the heat budget}

The circulation in the temperature-depth diagram describing each individual diabatic process is given in Fig. 4 and their associated heat transports calculated using Eq. (3) are shown in Fig. 5. Diabatic processes comprise all of the tendency terms listed on the right-hand side of Eq. (1), except for the advection term. The mixing terms are DIA, ISO, KPP, SIGMA_DIFF, and CON. From the surface heat and mass flux terms we only consider SWP, RIV, and FRZ whereas SFC and PME are confined only to the air-sea interface.

As discussed in section 3d, the circulations in Fig. 4 are the temperature-depth circulations that describe the vertical heat transport affected by each diabatic process. DIA warms the deep ocean (Fig. 4a), so as a temperature-depth circulation it displays a thermally indirect circulation (clockwise) with a downward movement of warm water and upward movement of cold water. In contrast, ISO, CON, and KPP (Figs. 4b-d, respectively), for water above $0^{\circ} \mathrm{C}$, are thermally direct. Again, ISO is largely thermally direct over these temperatures since it is dominated by the mixing of cool fresh surface waters with warmer more saline deep waters along isopycnal in the Southern Ocean (Kuhlbrodt et al. 2015). Below $0^{\circ} \mathrm{C}$, DIA and ISO are both thermally indirect and are partially balanced by the thermally direct CON. CON parameterizes the effect of convection, which transfers buoyancy upward, since buoyancy is dominated by temperature, causes deeper water to cool and shallower water to warm (Fig. 4c) resulting in a thermally direct contribution to $\psi^{\text {dia }}$. SWP warms subsurface water with an apparent thermally indirect circulation within the upper $100 \mathrm{~m}$ (Fig. 4e), while the influence of SIGMA_DIFF is negligible (not shown). Other than SWP, the remaining surface flux terms do not contribute to the circulation in temperature-depth space since they have no subsurface expression.

\section{d. Balance of kinematic and thermodynamic processes in individual cells}

Overall, the heat flux due to the diathermal circulation is downward in the upper $2000 \mathrm{~m}$ and upward below $2000 \mathrm{~m}$ (Fig. 5a). The vertical structure of this heat flux is similar to previously reported results about the residual circulation (Zika et al. 2013a, 2015). In the upper $100 \mathrm{~m}$, DIA, SWP and the total $\psi^{\text {dia }}$ transfer heat downward while KPP and ISO transfer heat upward. Between 100 and $2000 \mathrm{~m}$, the total $\psi^{\text {dia }}$ and DIA transport heat downward, and the remaining diabatic processes transport heat upward from the deep ocean. ISO has the largest contribution to this upward heat transport. Below $2000 \mathrm{~m}$, heat is transported upward by $\psi^{\mathrm{dia}}$ and is mainly balanced by DIA as in the classical advective-diffusive balance (Stommel and Arons 1960; Munk 1966; Munk and Wunsch 1998).

We decompose $\psi^{\text {dia }}$ into individual cells: a surface cell, a deep cell and a bottom cell, then calculate how kinematic and thermodynamic processes balance each other within each cell. The heat transport by the surface, deep and bottom cells were computed following Zika et al. (2013a) by integrating over each cell with respect to temperature at constant depth using Eq. (3) and with the following conditions: 
(a) Mean Circulation

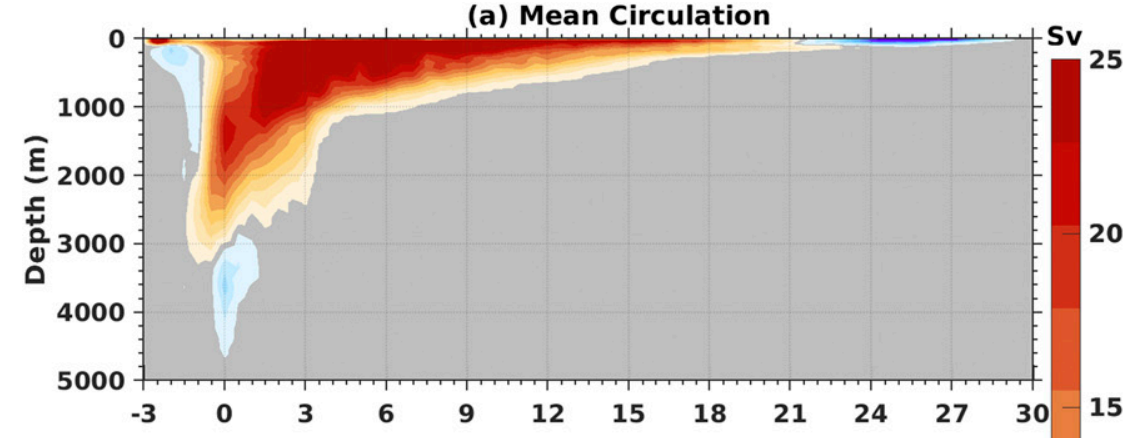

(b) Mesoscale Circulation

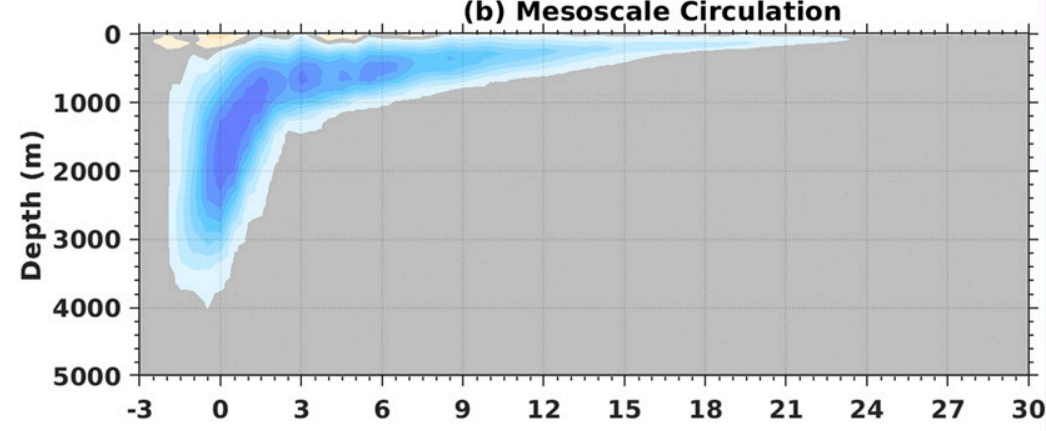

(c) Submesoscale Circulation
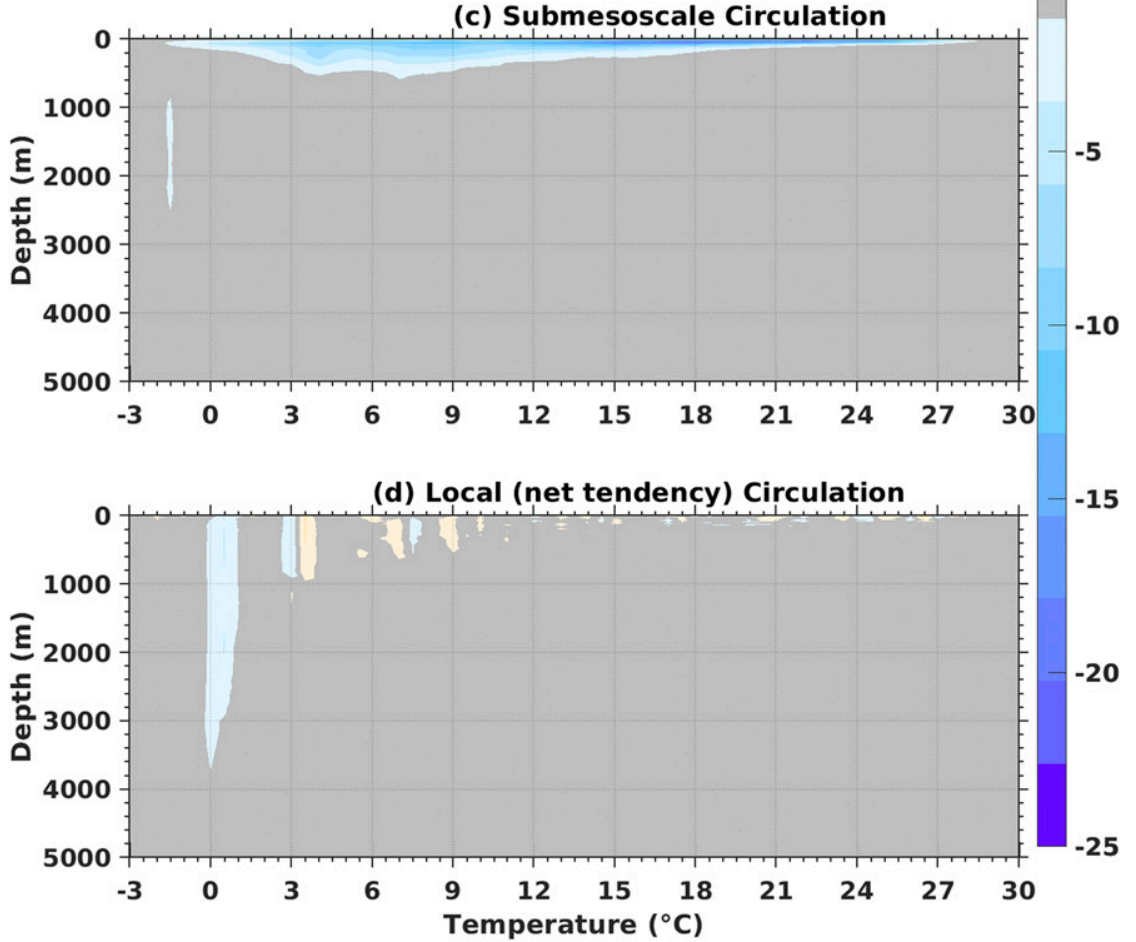

FIG. 3. Overturning circulation (Sv) in temperature $\left({ }^{\circ} \mathrm{C}\right)$-vs-depth $(\mathrm{m})$ coordinates due to (a) Eulerian mean, (b) mesoscale, and (c) submesoscale advective tendencies and (d) the Eulerian local time tendency. Positive (red) values show clockwise (thermally indirect) circulation, and negative (blue) cells are anticlockwise (thermally direct). 
(a) DIA Mixing

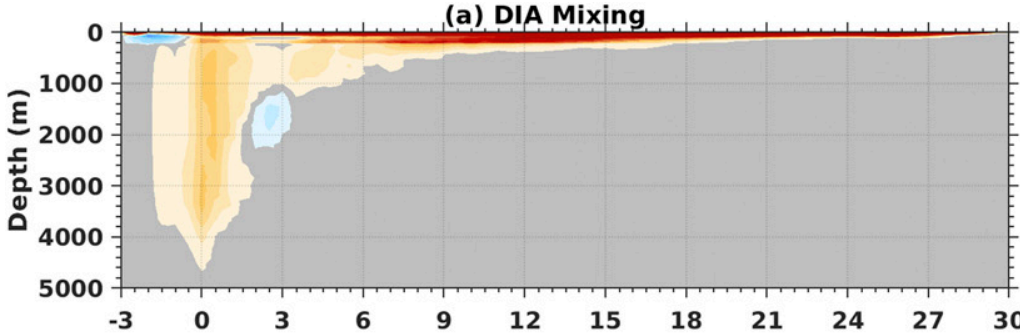

(b) ISO Mixing
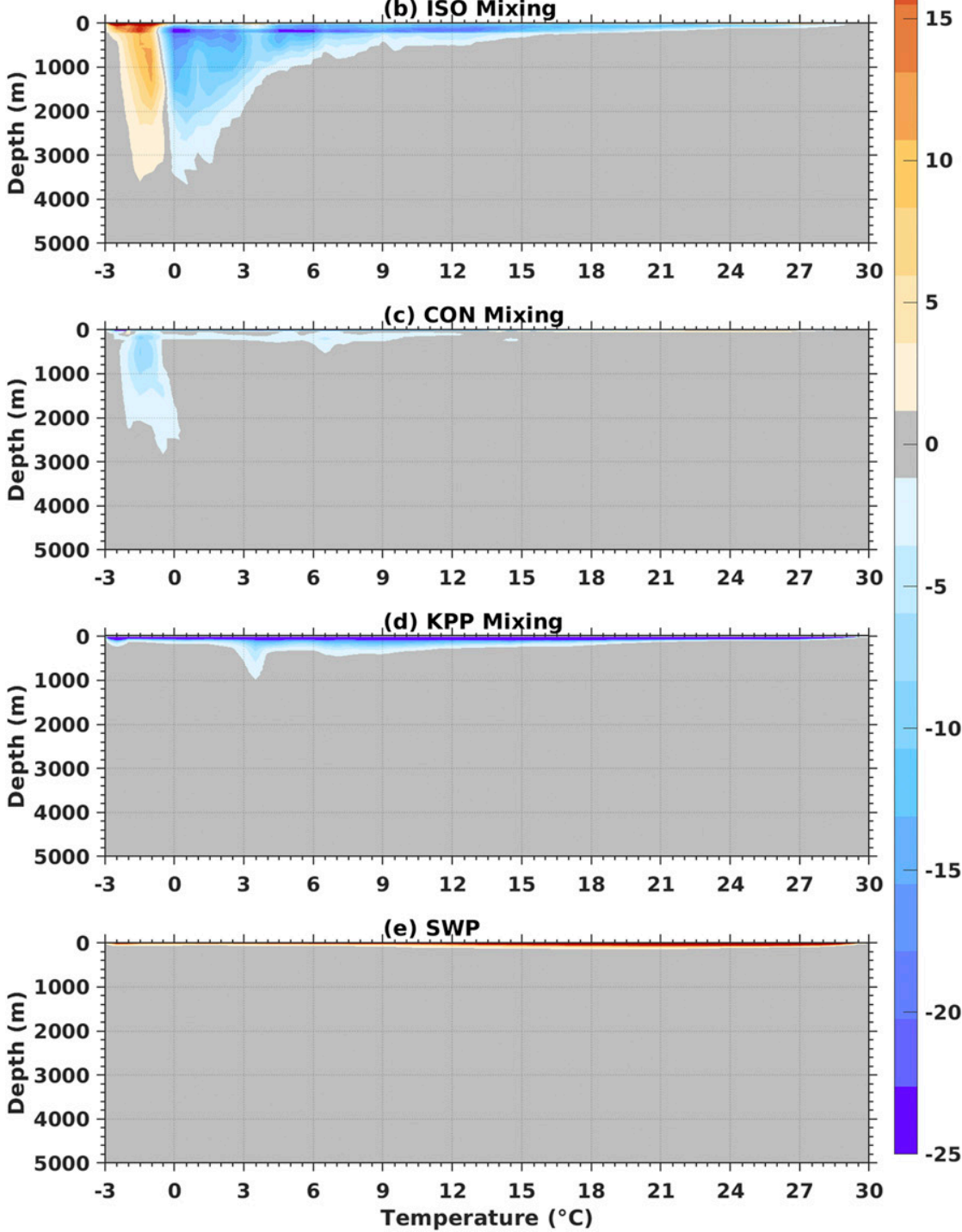

FIG. 4. Overturning circulation (Sv) implied by each diabatic term in the temperature tendency budget: (a) diapycnal mixing, (b) isopycnal mixing, (c) convection, (d) KPP mixing, and (e) short wave penetration. The remaining air-sea heat flux terms imply movement of water to different temperatures only in the shallowest layer of the ocean model and are not shown. Positive (red) values show clockwise (thermally indirect) circulation, and negative (blue) cells are anticlockwise (thermally direct). 
(a) Diathermal Circulation and Diabatic Process

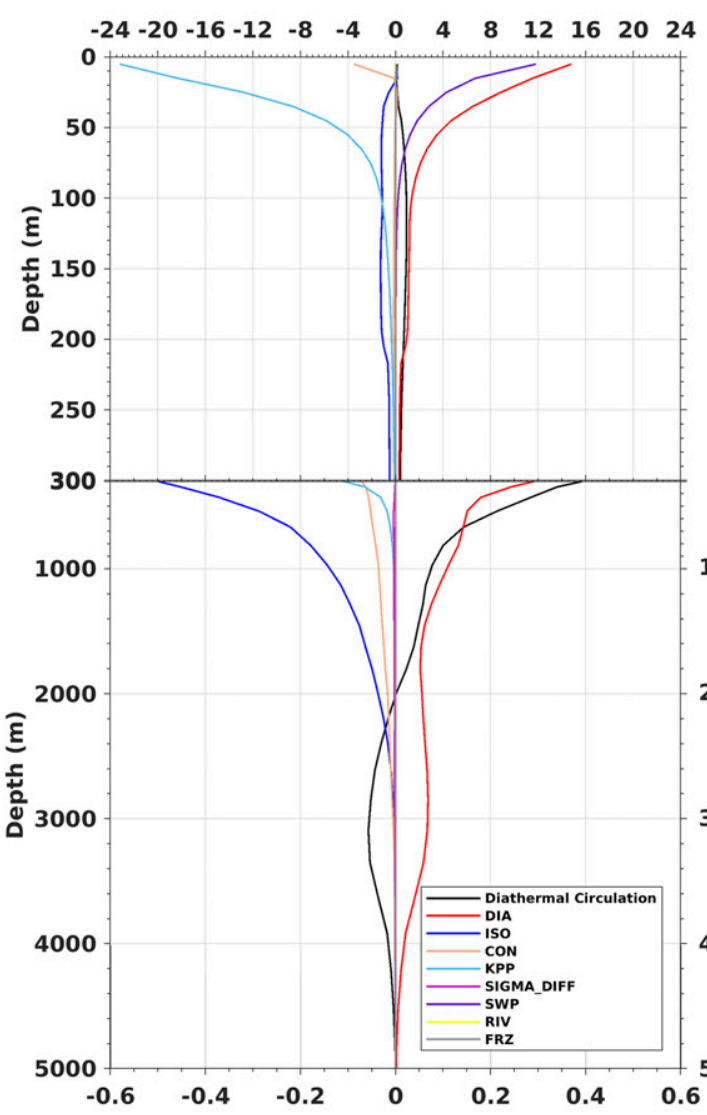

(c) Thermally Direct (Bottom) Cell and Diabatic Process

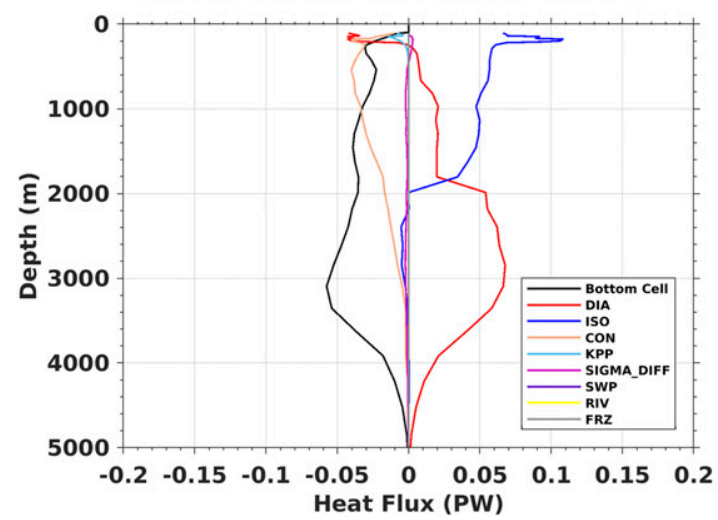

(b) Thermally Indirect (Deep) Cell and Diabatic Process

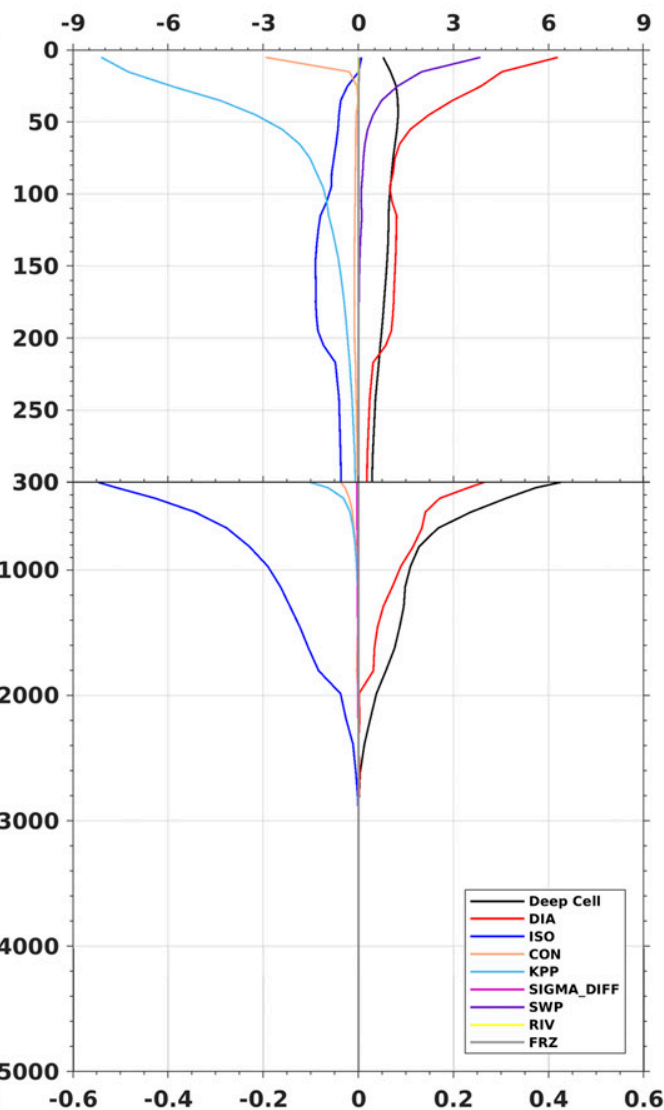

(d) Thermally Direct (Surface) Cell and Diabatic Process

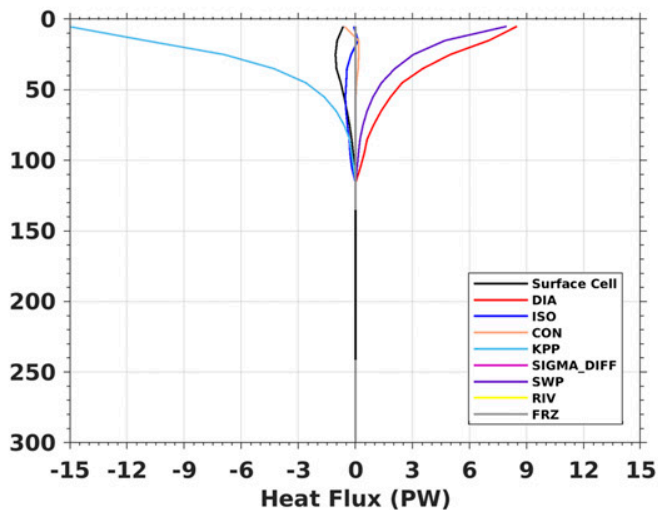

FIG. 5. (a) The vertical heat transport (PW; positive downward) due to individual diabatic processes and the sum of advective processes and the local trend (diathermal circulation). Also shown is the heat transport due to individual overturning circulation cells of the diathermal circulation shown in Fig. $2 \mathrm{c}$ and by corresponding diabatic process within those cells. They are (b) the thermally indirect deep cell, (c) the thermally direct bottom cell, and (d) the thermally direct surface cell. 
(a) Super Residual Circulation (Inc. SUB)

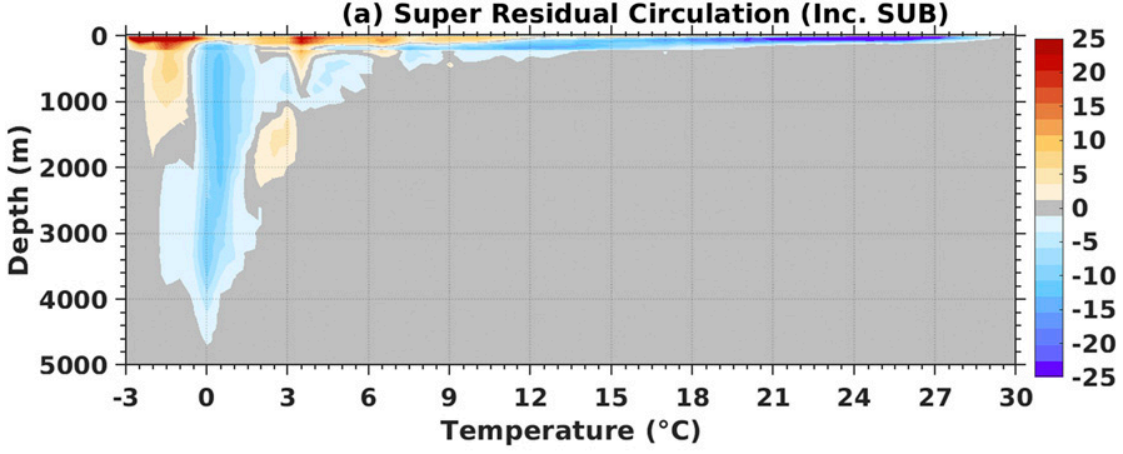

(b)

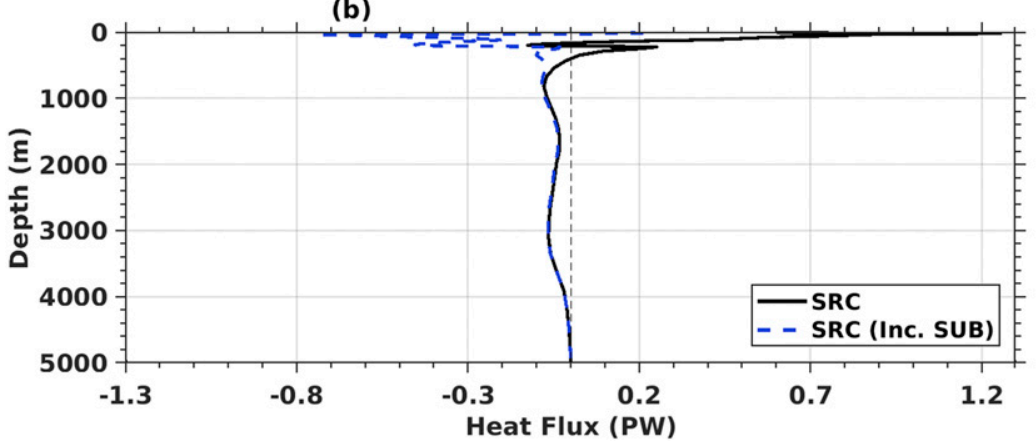

FIG. 6. (a) The SRC $\psi^{\mathrm{SRC}}(\mathrm{Sv})$; (b) the associated vertical heat transport SRC (PW; positive downward) for ACCESS-OM2.

1) the surface cell is where $\psi^{\text {dia }}<0$ and $\Theta>15^{\circ} \mathrm{C}$,

2) the deep cell is where $\psi^{\mathrm{dia}}<0$, for all $\Theta$, and

3) the bottom cell is where $\psi^{\text {dia }}<0$ and $\Theta<3^{\circ} \mathrm{C}$.

In a similar way we have also calculated the contributions to vertical heat transport associated with each diabatic process within each cell (Figs. 5b-d). The sum of heat transports by a particular diabatic process over all cells gives the total vertical heat transport attributable to that process.

The thermally indirect deep cell transports heat downward from the sea surface to $\sim 2500 \mathrm{~m}$ (Fig. $5 \mathrm{~b}$ ). DIA also constitutes a downward flux of heat and the two are completely balanced by ISO except in the upper $150 \mathrm{~m}$ where KPP and CON also contribute to an upward heat transport. Here, downward heat transport by the thermally indirect deep cell, which has been associated with interhemispheric overturning circulation (Zika et al. 2013a), is largely balanced by isopycnal mixing in the Southern Ocean (not shown).

The thermally direct bottom cell transports heat upward from the seafloor at $\sim 5000 \mathrm{~m}$ to near the sea surface (Fig. $5 \mathrm{c}$ ). Convection $(\mathrm{CON})$ also contributes substantially to the upward heat transport from deep ocean to surface. These terms are balanced by both ISO and DIA, which transport heat downward. In the upper $1800 \mathrm{~m}$, the vertical heat flux associated with ISO is larger than DIA. Below 2000-m depth, DIA dominates the downward heat transport, entirely balancing the upward heat transport by the cold cell below $3000 \mathrm{~m}$ where CON tapers to zero. In this model the bottom cell, which has been associated with Antarctic Bottom Water (Zika et al. 2013a), is not only balanced by diapycnal mixing, as expected (e.g., De Lavergne et al. 2016) but also isopycnal mixing.
The thermally direct surface cell is confined to above 200-m depth and transports heat upward peaking at $\sim 1.2 \mathrm{PW}$ at $40-\mathrm{m}$ depth (Fig. 5d). KPP and ISO also transport heat upward and are balanced by SWP and DIA. Therefore, in this circulation, which has been associated with subtropical gyres (Zika et al. 2013a), upward heat transport by the thermally direct surface cell combined with KPP is balanced by shortwave penetration and diapycnal diffusion.

\section{e. $S R C$}

The SRC is represented by the sum of the advective terms (resolved and parameterized advection) along with eddy mixing terms in Eq. (9). The SRC quantifies the equivalent circulation to that which would be measured were the eddies represented by parameterizations explicitly resolved in our model. The dominant feature of the SRC is a thermally direct cell extending throughout the entire water column (Fig. 6a), with $\sim 11 \mathrm{~Sv}\left(1 \mathrm{~Sv} \equiv 10^{6} \mathrm{~m}^{3} \mathrm{~s}^{-1}\right)$ of water downwelling near $0^{\circ} \mathrm{C}$ and upwelling around $2^{\circ} \mathrm{C}$, across the 1000-m depth surface. The addition of the ISO term to the advective terms to make the SRC clearly turns the largely thermally indirect diathermal circulation of the majority of the ocean to a thermally direct flow. That is, the heat transported downward by the Eulerian and eddy driven circulation associated with the upper cell of the overturning is more than counteracted by heat transport by isopycnal mixing.

There is also a substantial thermally indirect cell at temperatures colder than $0^{\circ} \mathrm{C}$, from the surface to a maximum depth of $2000 \mathrm{~m}$, with a peak transport of $23 \mathrm{~Sv}$ above $200 \mathrm{~m}$ but reducing to around $10 \mathrm{~Sv}$ over the $200-1500-\mathrm{m}$ depth range. 
The deep warming of this thermally indirect SRC likely balances the strong deep cooling achieved by thermally direct convection (CON).

We have calculated the vertical heat transport due to the SRC using Eq. (3), giving the SRT (Fig. 6b). Our resulting SRT is qualitatively similar to those reported by Dias et al. (2020a), although here our SRC is transporting heat upward at nearly all depths due to the inclusion of SUB in our analysis (blue line, Fig. 6b), as explained in section $3 d$. Since SUB is only nonzero near the surface (Fig. 3c), below $700 \mathrm{~m}$, the SRC with and without SUB included are identical (blue and black line, Fig. 6b).

Unlike previous studies that derived a single depth dependent curve for global SRT, here because we have described superresidual processes with a streamfunction, we can separate the heat transport due to distinct components of the circulation (Ferrari and Ferreira 2011; Zika et al. 2013a). In Fig. 7, we separate the heat transport associated with the SRC's thermally direct $\left(\psi^{\mathrm{SRC}}<0\right)$ and indirect $\left(\psi^{\mathrm{SRC}}>0\right)$ components (these are closed anticlockwise and clockwise circulation cells in Fig. 6, respectively) as well as the corresponding heat transport by each diabatic process in each cell.

The thermally direct component of the SRC transports heat upward throughout the water column (Fig. 7b). This heat transport is compensated by diapycnal diffusion (DIA) at all depths that transports heat downward. Here the SRC is dominated by a thermally direct cell that is largely balanced by vertical heat transport due to small-scale mixing. The SRC therefore describes a circulation that conforms to the overturning circulation envisaged in classical advectivediffusive balance (Stommel and Arons 1960; Munk 1966; Munk and Wunsch 1998). However, comparison with the $\psi^{*}$, which is largely thermally indirect, suggests that isopycnal mixing is doing as much or more of the stabilizing vertical heat transport required to balance the effect of small-scale three-dimensional mixing than resolved and parameterized advection combined.

The thermally indirect component of the SRC transports heat downward (Fig. 7c). This circulation is largely found in the upper $2000 \mathrm{~m}$ of the ocean and at temperatures less than $0^{\circ} \mathrm{C}$, suggesting it is associated with regions of bottom and deep waters formation. The vertical heat transport of the thermally indirect cell of SRC and DIA are mostly compensated by KPP near the surface and CON down to $2000 \mathrm{~m}$, which move heat upward.

Overall, our diagnosis of the contribution of individual circulation cells and individual diabatic processes to the superresidual heat transport expands on the analysis of Dias et al. (2020a). Namely, we have shown that the SRT has two major contributors, one that transports heat upward and the other that transports it downward, with differing balancing diabatic processes.

\section{f. SRC comparisons across the different configurations of the ACCESS model}

Here, we compare the SRC and associated heat transport across three different configurations of the ACCESS model (Kiss et al. 2020, as introduced in their section 2), with $1^{\circ}$
(ACCESS-OM2-1), $0.25^{\circ}$ (ACCESS-OM2-025), and $0.1^{\circ}$ (ACCESS-OM2-01) resolutions, as shown in Fig. 8. The $\mathrm{SRC}$ is dominated by a thermally direct cell, i.e., buoyancydriven in all three resolutions at temperatures between 0 and $3^{\circ} \mathrm{C}$, from $200 \mathrm{~m}$ to the seafloor (Figs. $8 \mathrm{a}-\mathrm{c}$ ). At $1^{\circ} \mathrm{C}$ and a depth of $1000 \mathrm{~m}$ (the approximate depth of the maximum of the thermally direct cell in colder temperature), ACCESSOM2-1, ACCESS-OM2-025, and ACCESS-OM2-01 respectively transport 13,5 , and $20 \mathrm{~Sv}$ of cold water downward. In other words, the thermally direct cell in the ACCESS-OM2-01 is $\sim 4$ times as large as in ACCESS-OM2-025 and $\sim 1.5$ times as large as in ACCESS-OM2-1.

The strongest thermally direct cell occurs in the highestresolution model (ACCESS-OM2-01), which has been noted for its relatively high Antarctic Bottom Water (AABW) formation (Kiss et al. 2020). However, a linear relationship between horizontal resolution and strength of the thermally direct cold cell is not seen. The $0.25^{\circ}$ (ACCESS-OM2-025) is an outlier, within which mesoscale eddies are partially resolved and partially parameterized using a weak coefficient of eddy advection and eddy diffusion (Table 1; Kiss et al. 2020). Indeed, the difficulties of balancing resolved and subgridscale processes at $0.25^{\circ}$, especially in the Southern Ocean, are well known (Farneti et al. 2015).

The other notable difference between the $0.1^{\circ}$ and coarserresolution models is the occurrence of thermally indirect cells either side of the main thermally direct cell (Figs. 8a-c). ACCESS-OM2-01 for example lacks a thermally indirect cell at low temperatures (below $0^{\circ} \mathrm{C}$ ). These thermally indirect cells occur in ACCESS-OM2-1 and ACCESS-OM2-025 because of a balance of parameterized isopycnal mixing and parameterized convection. This cell may not be present in ACCESS-OM2-01 because it is able to better resolve water mass formation processes near the Antarctic coast (e.g., coastal polynyas, greater sea ice production and associated brine rejection) and flows down the continental slope as compared with the lower-resolution models, which tend to favor open ocean convection (Kiss et al. 2020). Though, we cannot rule out the shorter spinup time in ACCESS-OM2-01 being a factor. For the warmer indirect cells (around $3^{\circ} \mathrm{C}$ ) the appearance is only weak in the $1^{\circ}$ model. While the problems of $0.25^{\circ}$ models discussed above make interpretation more difficult, it is clear that penetration of heat from the surface to at least $1000 \mathrm{~m}$ (red cells) is much stronger in ACCESS-OM2-025 than in either the coarser- or finer-resolution configurations.

The vertical heat transport due to the SRC is shown in Figs. 8a-c using Eq. (3) and is shown in Fig. 8d. Heat is transported upward in each of the configurations, where SRC cools the deep ocean and warms the ocean surface. In ACCESS-OM2-1 and ACCESS-OM2-025, however, the SRC transports heat downward in the upper $200 \mathrm{~m}$. In ACCESSOM2-01, the SRC heat transport is $\sim 1.5$ times as large as in ACCESS-OM2 and $\sim 4$ times as large as in ACCESS-OM2025 at $1000 \mathrm{~m}$ (Fig. 8d).

These relative magnitudes of the vertical heat transport across different resolutions are consistent with the relative strengths of the dominant thermally direct cells (Figs. 8a-c), with the much weaker overall vertical heat transport in the 
(a) SRC and Non-Advective Process

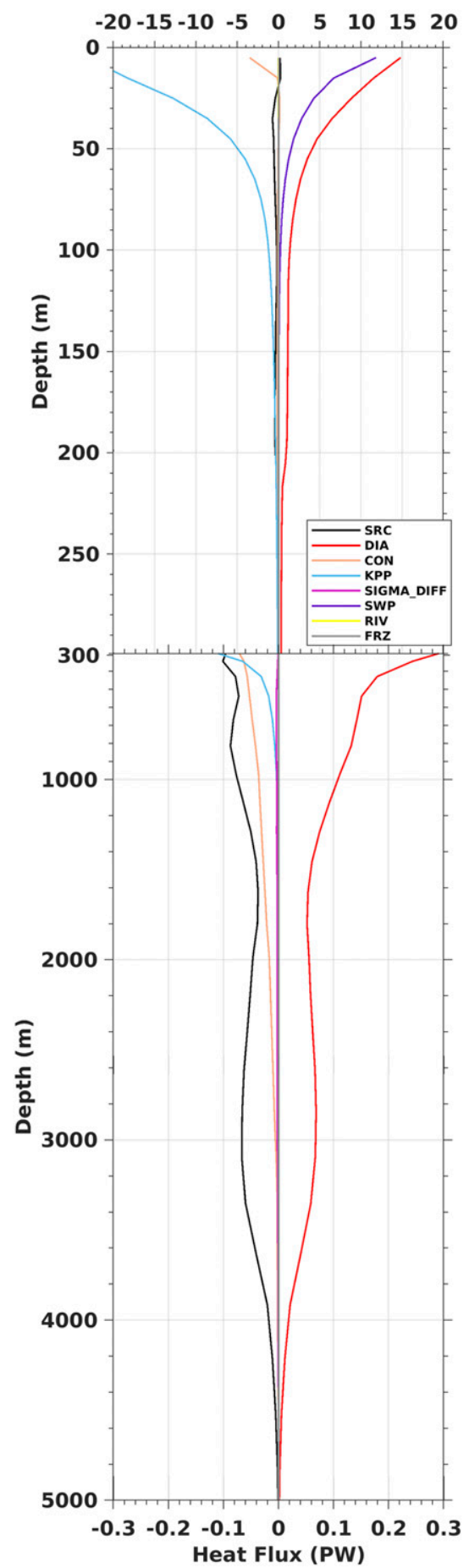

(b)Thermally Direct Cell and Non-Advective Process (c) Thermally Indirect cell and Non-Advectiove Process

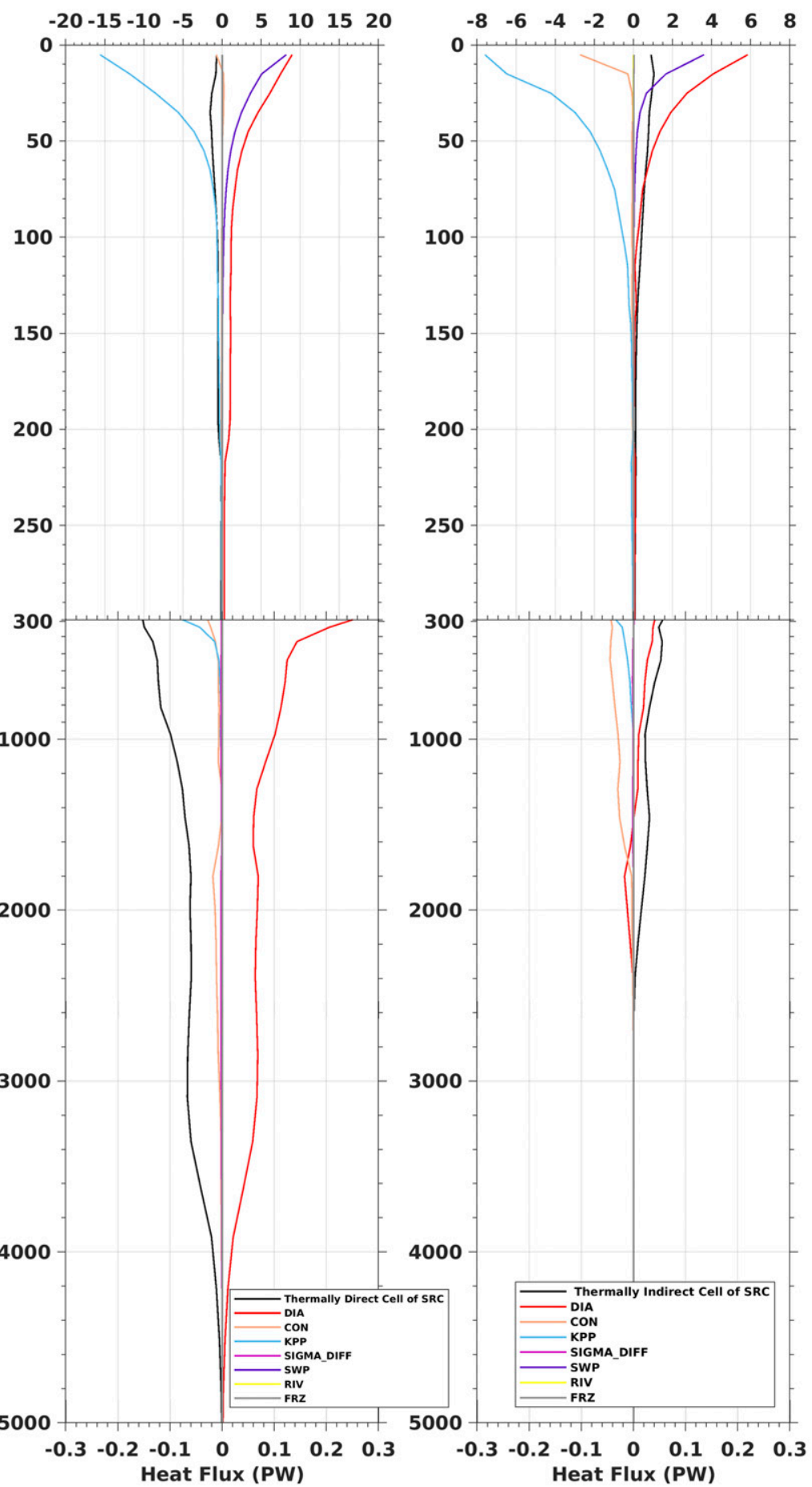

FIG. 7. (a) The vertical heat transport (PW; positive downward) due to the SRC and by individual diabatic processes. Also shown is the heat transport due to individual SRC cells and by corresponding diabatic processes within those cells. They are (b) the thermally direct cell (cold) of SRC and (c) the thermally indirect (warm) cell of SRC. 
(a) ACCESS-OM2-1 ${ }^{\circ}$

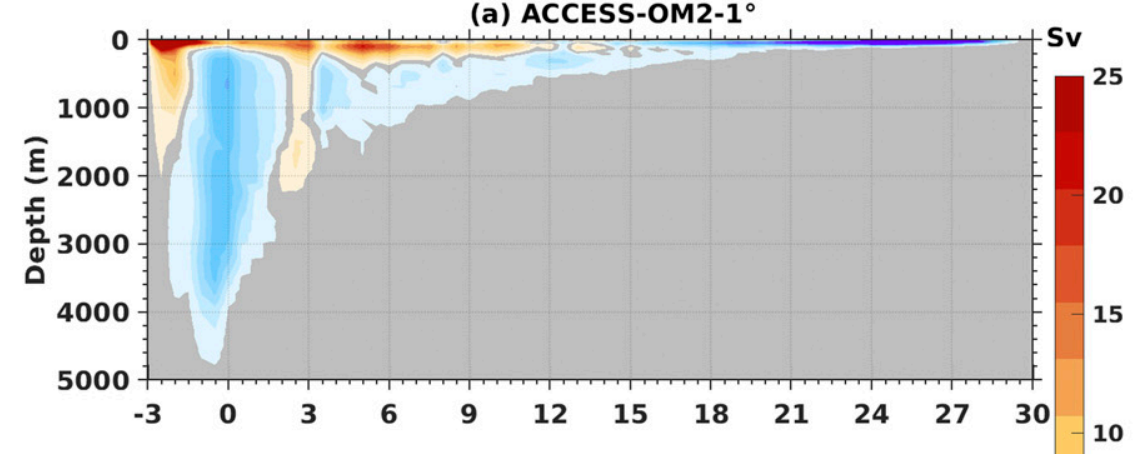

(b) ACCESS-OM2-025 ${ }^{\circ}$

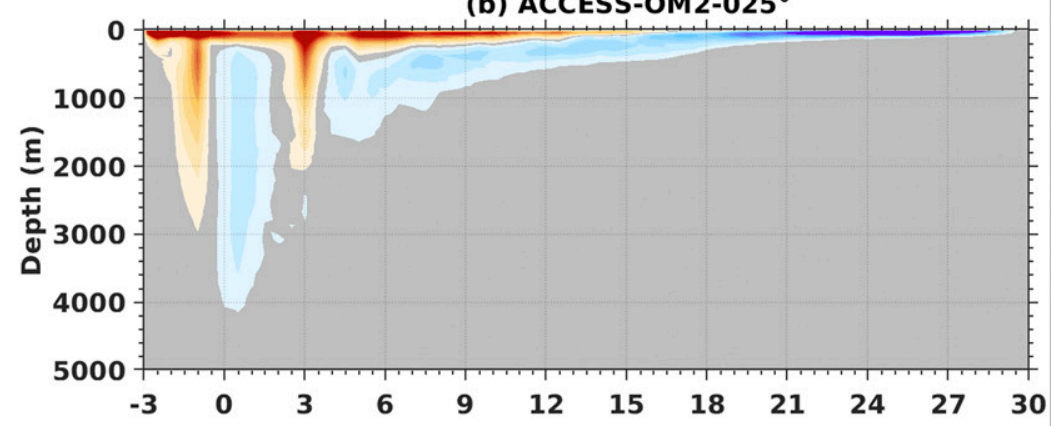

(c) ACCESS-OM2-01 ${ }^{\circ}$

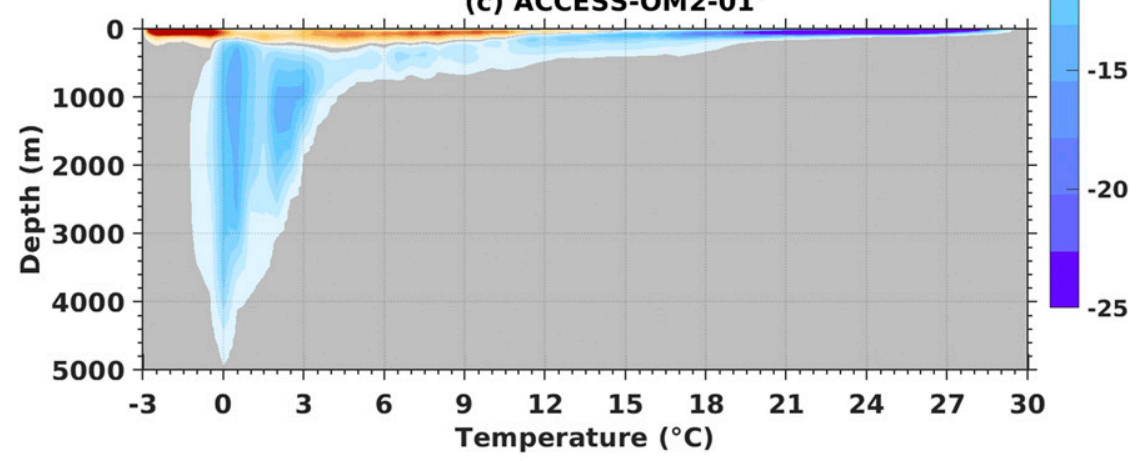

(d) Vertical heat transport

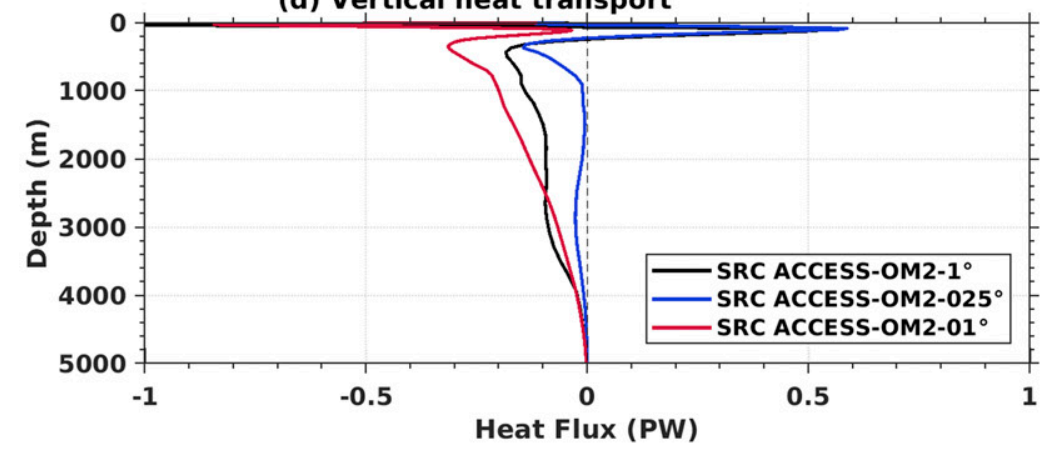

FIG. 8. The SRC $\psi^{\mathrm{SRC}}$ (Sv) for (a) ACCESS-OM2-1, (b) ACCESS-OM2-025, and (c) ACCESS-OM2-01 and (d) its vertical heat transport SRC (PW; positive downward). The SRC term shown here includes submesoscale advection. 
$0.25^{\circ}$ model clearly influenced by the compensating downward heat transports of that model's thermally indirect cells.

\section{Discussion and conclusions}

We have investigated the mechanisms of vertical heat transport in ACCESS-OM simulations using a framework that projects ocean circulation and diabatic processes into temperature and depth coordinates. This framework allows us to elucidate the role of different physical processes in setting the ocean's overturning in this space and the consequent vertical heat transport. Our approach complements previous understanding from standard tracer budget methods (Gregory 2000; Gnanadesikan et al. 2005; Wolfe et al. 2008; Hieronymus and Nycander 2013; Exarchou et al. 2015; Griffies et al. 2015). For the first time, we introduce the use of temperature advective tendencies to quantify the ocean overturning circulation and the roles of mean and eddy advection. Furthermore, we have derived equivalent circulations describing parameterized processes and presented the SRC.

By analyzing the last 20 years of ACCESS-OM2 simulations, we found that residual circulation using residual vertical velocity $\psi$ displays two thermally direct (bottom and surface) and a thermally indirect (deep) cell, as in Zika et al. (2013a). We computed this residual circulation using the advective temperature tendency $\psi^{*}$. While the $\psi^{*}$ approach displays similar thermally direct and indirect cells, the $\psi^{*}$ approach is superior because it allows closure of the heat budget. We found that heat transport using $\psi$ and $\psi^{*}$ is not similar across all depths. The approach underestimates upward heat transport in the upper $2000 \mathrm{~m}$ and overestimates in the deep ocean relative to $\psi^{*}$. The largest differences between $\psi$ and $\psi^{*}$ occur at the 1000-m depth (i.e., $\psi$ transports 0.01 PW heat downward, whereas $\psi^{*}$ transports $0.07 \mathrm{PW}$ heat) and 3000-m depth (i.e., $\psi$ transports $0.09 \mathrm{PW}$ heat upward whereas $\psi^{*}$ transports 0.07 PW) (Fig. 2).

For the ACCESS-OM2 simulations we added together the residual circulation $\psi^{*}$ and local tendency terms to construct what we call a diathermal circulation [Eq. (6)]. As noted above, the residual and diathermal circulations are quite similar. This is because the local tendency term makes only a very small contribution. We found (Fig. 5a) that the diathermal circulation transports heat downward in the upper $2000 \mathrm{~m}$ and is primarily balanced by isopycnal diffusion (ISO), however, in the deep ocean it transports heat upward and is balanced by diapycnal diffusion (DIA). The downward heat transport by the thermally indirect deep cell has been linked to the interhemispheric meridional overturning circulation (Zika et al. 2013a) and is balanced by isopycnal diffusion (ISO) in ACCESSOM2 (Fig. 5b). Furthermore, upward heat transport by the thermally direct bottom cell, which has been linked to the Antarctic Bottom Water circulation (Zika et al. 2013a), is balanced in the upper $2000 \mathrm{~m}$ by downward heat transport due to isopycnal diffusion, and by diapycnal diffusion deeper down (Fig. 5c).

The concept of an SRT (sum of the mean and parameterized eddy advection and eddy diffusion tendency terms) was first introduced by Kuhlbrodt et al. (2015) and recently explored by
Dias et al. (2020a) using ACCESS-OM2. Here we have used the same simulation as Dias et al. (2020a) allowing direct comparison. Under quasi-steady state, Dias et al. (2020a) concluded that SRT moves heat downward in the mixed layer and upward within the ocean interior. In our analysis, the SRT, when projected onto temperature and depth coordinates, gives the SRC under quasi-steady state. It is represented by two cells, one that transports heat downward (thermally indirect) and the other that transports it upward (thermally direct).

A minor distinction between the suite of processes we classify as SRC and those used by the authors mentioned above is that we have included submesoscale advection (SUB) as part of the SRC. Although SUB is parameterized as skew diffusion in ACCESS it can be interpreted as an advective process and is typically captured in diagnostics of the residual ocean circulation (Kuhlbrodt et al. 2015; Zika et al. 2015). We therefore opted to include it in the SRC. In previous studies, the focus was on large-scale advection (Dias et al. 2020a,b). As expected, influence of SUB is only substantive within mixed layers.

The diathermal circulation, which includes Eulerian and eddy induced advection, is dominated by a thermally indirect cell. On the other hand, the SRC, which combines the Eulerian mean advection and eddy induced advection with eddy mixing, is dominated by a thermally direct cell. We found that the SRC drives $11 \mathrm{~Sv}$ of cold water downwelling close to $\sim 0^{\circ} \mathrm{C}$ and upwelling at $\sim 2^{\circ} \mathrm{C}$ across the $1000-\mathrm{m}$ depth surface. This description of a dominant thermally direct overturning is reminiscent of the classical descriptions of ocean circulation as a deep-reaching circulation balanced by vertical mixing (Munk 1966). Our results suggest that the classical description of a thermally direct circulation balanced by small-scale mixing is possible, but that the contribution of isopycnal mixing to the downward transport of cold and upward transport of warm water (which is captured by the SRC but not $\psi^{*}$ ) may be an essential component of that circulation.

We also found a thermally indirect cell component of the SRC in ACCESS at temperatures below $0^{\circ} \mathrm{C}$. This thermally indirect cell of SRC in fact transports heat downward in the upper $2000 \mathrm{~m}$. We found that this downward heat transport at cold temperatures is balanced by convection, which fluxes heat upward at these temperatures (Fig. 6a and Fig. 4c). However, coarse-resolution models such as the $1^{\circ}$ ACCESS-OM2- 1 do not adequately resolve coastal polynyas and downslope convection processes and further investigation is needed to see if this is a robust feature. For example, this thermally indirect cell was not present in the fine-resolution ACCESSOM2-01 simulation.

Although the SRC is qualitatively similar across ACCESS configurations with different horizontal grid resolutions, there are important quantitative differences in vertical heat transport. The SRC's upward heat transport is about 4 times as large in ACCESS-OM2-01 as in ACCESS-OM2-025 and about 1.5 times as large as in ACCESS-OM2-1. Because horizontal resolution is not the only difference (e.g., spinup length), a further investigation (beyond the scope of this paper) is required to identify the key influencing factors.

Dias et al. (2020a) suggested that Kuhlbrodt et al.'s (2015) SRT concept - the combination of the residual circulation with 
eddy mixing - could be used to compare models of varying horizontal resolution, in which the partition of the resolved and parameterized terms differs. This partially motivated our extension of the SRT concept into the SRC in temperature-depth space, where insights into water mass pathways can be gained.

One important benefit of the formalism we have put forward is that the circulation implied by any parameterized processes can be diagnosed in temperature-depth space. A possible application of this would be comparison between directly simulated and parameterized convection (e.g., Sohail et al. 2019). In ACCESS-OM2, if we were to include the impact of convection together with the remaining processes making up the SRC (i.e., combining the circulations in Fig. 4c with Fig. 6a) this would largely cancel out the cold thermally indirect component of the SRC that we saw in ACCESS-OM2 (a circulation combining SRC and convective processes could be called "super-duper residual circulation"). The finer versions of ACCESS (ACCESS-OM2-01) does not display this thermally indirect cell at colder temperatures (Fig. 8a). Obviously, the finer-resolution model does not resolve small-scale convection, but its ability to describe some downslope flows explicitly may be negating the need for parameterized open ocean convection.

There are limitations to our comparison across the different resolutions of ACCESS-OM2 as the different model experiments have different spinup lengths, topography, and some model parameters. This may alter some of the conclusions presented here. In our ACCESS model, the heat budget is closed but the local tendency term is not exactly zero, indicating that there is some drift in our models. Although, we have used monthly temperature tendencies calculated online in ACCESS, we use offline binning into temperature coordinates. This can affect the calculation of individual circulation cells and their heat transport.

The framework we have put forward allows for the interpretation of diabatic processes in ocean-climate models. These processes have been found to be key to differences between model responses to climate forcing (Couldrey et al. 2021; Todd et al. 2020). Therefore, it will be interesting to use the SRC framework to compare models and understand their spread.

Acknowledgments. Authors Savita and Boeira Dias are supported by a Tasmanian Graduate Research Scholarship and CSIRO-UTAS Quantitative Marine Science top-up. Author Zika was supported by the Australian Research Council (ARC; DP160103130 and DP190101173). Author Marsland is supported by projects jointly funded through CSIRO and the Earth Systems and Climate Change Hub of the Australian Government's National Environmental Science Programme. Author Domingues was supported by the ARC (FT130101532 and DP160103130) and U.K.'s Natural Environment Research Council (NE/P019293/1). We are thankful for support from the Consortium for Ocean-Sea Ice Modelling in Australia (COSIMA). This research was undertaken with the support of resources and services from the National Computational Infrastructure (NCI), which is supported by the Australian Government. The model output and configuration files are available upon reasonable request to the corresponding author.

\section{REFERENCES}

Adcroft, A., and J.-M. Campin, 2004: Rescaled height coordinates for accurate representation of free-surface flows in ocean circulation models. Ocean Modell., 7, 269-284, https://doi.org/ 10.1016/j.ocemod.2003.09.003.

Arakawa, A., and V. R. Lamb, 1977: Computational design of the basic dynamical processes of the UCLA general circulation model. General Circulation Models of the Atmosphere, J. Chang, Ed., Methods in Computational Physics: Advances in Research and Applications, Vol. 17, Academic Press, 173265, https://doi.org/10.1016/B978-0-12-460817-7.50009-4.

Beckmann, A., and R. Döscher, 1997: A method for improved representation of dense water spreading over topography in geopotential-coordinate models. J. Phys. Oceanogr., 27, 581-591, https://doi.org/10.1175/1520-0485(1997)027<0581: AMFIRO $>2.0 . \mathrm{CO} ; 2$.

Bi, D., and Coauthors, 2013: ACCESS-OM: The ocean and sea-ice core of the ACCESS coupled model. Aust. Meteor. Oceanogr. J., 63, 213-232, https://doi.org/10.22499/2.6301.014.

Church, J. A., and Coauthors, 2013: Sea level change. Climate Change 2013: The Physical Science Basis, T. F. Stocker and Coauthors, Cambridge University Press, 1137-1216.

Couldrey, M. P., and Coauthors, 2021: What causes the spread of model projections of ocean dynamic sea-level change in response to greenhouse gas forcing? Climate Dyn., 56, 155-187, https://doi.org/10.1007/s00382-020-05471-4.

De Lavergne, C., G. Madec, J. Le Sommer, A. G. Nurser, and A. C. Naveira Garabato, 2016: On the consumption of Antarctic Bottom Water in the abyssal ocean. J. Phys. Oceanogr., 46, 635-661, https://doi.org/10.1175/JPO-D-14-0201.1.

Dias, F. B., C. M. Domingues, S. J. Marsland, S. Griffies, S. Rintoul, R. Matear, and R. Fiedler, 2020a: On the superposition of mean advective and eddy-induced transports in global ocean heat and salt budgets. J. Climate, 33, 1121-1140, https:// doi.org/10.1175/JCLI-D-19-0418.1.

- , and Coauthors, 2020b: Ocean heat storage in response to changing ocean circulation processes. J. Climate, 33, 90659082, https://doi.org/10.1175/JCLI-D-19-1016.1.

Domingues, C. M., S. E. Wijffels, M. E. Maltrud, J. A. Church, and M. Tomczak, 2006: Role of eddies in cooling the Leeuwin Current. Geophys. Res. Lett., 33, L05603, https://doi.org/ 10.1029/2005GL025216.

Exarchou, E., T. Kuhlbrodt, J. M. Gregory, and R. S. Smith, 2015: Ocean heat uptake processes: A model intercomparison. J. Climate, 28, 887-908, https://doi.org/10.1175/JCLI-D-14-00235.1.

Ferrari, R., and D. Ferreira, 2011: What processes drive the ocean heat transport? Ocean Modell., 38, 171-186, https://doi.org/ 10.1016/j.ocemod.2011.02.013.

— S. M. Griffies, A. G. Nurser, and G. K. Vallis, 2010: A boundary-value problem for the parameterized mesoscale eddy transport. Ocean Modell., 32, 143-156, https://doi.org/ 10.1016/j.ocemod.2010.01.004.

Farneti, R., and Coauthors, 2015: An assessment of Antarctic Circumpolar Current and Southern Ocean meridional overturning circulation during 1958-2007 in a suite of interannual CORE-II simulations. Ocean Modell., 93, 84-120, https:// doi.org/10.1016/j.ocemod.2015.07.009.

Fox-Kemper, B., and Coauthors, 2011: Parameterization of mixed layer eddies. III: Implementation and impact in global ocean climate simulations. Ocean Modell., 39, 61-78, https://doi.org/ 10.1016/j.ocemod.2010.09.002.

Gent, P. R., and J. C. McWilliams, 1990: Isopycnal mixing in ocean circulation models. J. Phys. Oceanogr., 20, 150-155, 
https://doi.org/10.1175/1520-0485(1990)020<0150:IMIOCM > 2.0.CO;2.

_ _ J. Willebrand, T. J. McDougall, and J. C. McWilliams, 1995: Parameterizing eddy-induced tracer transports in ocean circulation models. J. Phys. Oceanogr., 25, 463-474, https:// doi.org/10.1175/1520-0485(1995)025<0463:PEITTI>2.0.CO;2.

Gnanadesikan, A., R. D. Slater, P. Swathi, and G. K. Vallis, 2005: The energetics of ocean heat transport. J. Climate, 18, 26042616, https://doi.org/10.1175/JCLI3436.1.

Gregory, J. M., 2000: Vertical heat transports in the ocean and their effect on time-dependent climate change. Climate Dyn., 16, 501-515, https://doi.org/10.1007/s003820000059.

Griffies, S. M., 1998: The Gent-McWilliams skew flux. J. Phys. Oceanogr., 28, 831-841, https://doi.org/10.1175/1520-0485(1998) 028<0831:TGMSF $>2.0 . \mathrm{CO} ; 2$.

— 2012: Elements of the Modular Ocean Model (MOM). GFDL Ocean Group Tech. Rep. 7, 632 pp., https://momocean.github.io/assets/pdfs/MOM5_manual.pdf.

__ , and R. J. Greatbatch, 2012: Physical processes that impact the evolution of global mean sea level in ocean climate models. Ocean Modell., 51, 37-72, https://doi.org/10.1016/ j.ocemod.2012.04.003.

—- A. Gnanadesikan, R. C. Pacanowski, V. D. Larichev, J. K. Dukowicz, and R. D. Smith, 1998: Isoneutral diffusion in a Z-coordinate ocean model. J. Phys. Oceanogr., 28, 805-830, https://doi.org/10.1175/1520-0485(1998)028<0805:IDIAZC > 2.0.CO;2.

— , and Coauthors, 2015: Impacts on ocean heat from transient mesoscale eddies in a hierarchy of climate models. J. Climate, 28, 952-977, https://doi.org/10.1175/JCLI-D-14-00353.1.

Groeskamp, S., J. D. Zika, T. J. McDougall, B. M. Sloyan, and F. Laliberté, 2014: The representation of ocean circulation and variability in thermodynamic coordinates. J. Phys. Oceanogr., 44, 1735-1750, https://doi.org/10.1175/JPO-D-13-0213.1.

— , S. M. Griffies, D. Iudicone, R. Marsh, A. G. Nurser, and J. D. Zika, 2019: The water mass transformation framework for ocean physics and biogeochemistry. Annu. Rev. Mar. Sci., 11, 271-305, https://doi.org/10.1146/annurev-marine-010318095421.

Hieronymus, M., and J. Nycander, 2013: The budgets of heat and salinity in NEMO. Ocean Modell., 67, 28-38, https://doi.org/ 10.1016/j.ocemod.2013.03.006.

Hogg, A. M., P. Spence, O. A. Saenko, and S. M. Downes, 2017: The energetics of Southern Ocean upwelling. J. Phys. Oceanogr., 47, 135-153, https://doi.org/10.1175/JPO-D-160176.1.

Holmes, R. M., J. D. Zika, and M. H. England, 2019a: Diathermal heat transport in a global ocean model. J. Phys. Oceanogr., 49, 141-161, https://doi.org/10.1175/JPO-D-18-0098.1.

,-- R. Ferrari, A. F. Thompson, E. R. Newsom, and M. H. England, 2019b: Atlantic Ocean heat transport enabled by Indo-Pacific heat uptake and mixing. Geophys. Res. Lett., 46, 13 939-13 949, https://doi.org/10.1029/2019GL085160.

Huber, M., R. Tailleux, D. Ferreira, T. Kuhlbrodt, and J. Gregory, 2015: A traceable physical calibration of the vertical advectiondiffusion equation for modeling ocean heat uptake. Geophys. Res. Lett., 42, 2333-2341, https://doi.org/10.1002/2015GL063383.

Hunke, E., W. Lipscomb, A. Turner, N. Jeffery, and S. Elliot, 2015: CICE: The Los Alamos Sea Ice Model documentation and software user's manual version 5.1. Los Alamos National Laboratory Tech. Rep. No. LA-CC-06-012, 665 pp.

Jackett, D. R., T. J. McDougall, R. Feistel, D. G. Wright, and S. M. Griffies, 2006: Algorithms for density, potential temperature, conservative temperature, and the freezing temperature of seawater. J. Atmos. Oceanic Technol., 23, 1709-1728, https:// doi.org/10.1175/JTECH1946.1.

Jochum, M., 2009: Impact of latitudinal variations in vertical diffusivity on climate simulations. J. Geophys. Res., 114, C01010, https://doi.org/10.1029/2008JC005030.

Kiss, A. E., and Coauthors, 2020: ACCESS-OM2 v1. 0: A global ocean-sea ice model at three resolutions. Geosci. Model Dev., 13, 401-442, https://doi.org/10.5194/gmd-13-401-2020.

Klinger, B. A., J. Marshall, and U. Send, 1996: Representation of convective plumes by vertical adjustment. J. Geophys. Res., 101, 18175-18182, https://doi.org/10.1029/96JC00861.

Kobayashi, S., and Coauthors, 2015: The JRA-55 reanalysis: General specifications and basic characteristics. J. Meteor. Soc. Japan, 93, 5-48, https://doi.org/10.2151/jmsj.2015-001.

Kuhlbrodt, T., and J. Gregory, 2012: Ocean heat uptake and its consequences for the magnitude of sea level rise and climate change. Geophys. Res. Lett., 39, L18608, https://doi.org/ 10.1029/2012GL052952.

_ _ _ _ and L. Shaffrey, 2015: A process-based analysis of ocean heat uptake in an AOGCM with an eddy-permitting ocean component. Climate Dyn., 45, 3205-3226, https:// doi.org/10.1007/s00382-015-2534-0.

Large, W. G., J. C. McWilliams, and S. C. Doney, 1994: Oceanic vertical mixing: A review and a model with a nonlocal boundary layer parameterization. Rev. Geophys., 32, 363-403, https://doi.org/10.1029/94RG01872.

Locarnini, R. A., and Coauthors, 2013: Temperature. Vol. 1, World Ocean Atlas 2013, NOAA Atlas NESDIS 73, 40 pp.

Munk, W. H., 1966: Abyssal recipes. Deep-Sea Res. Oceanogr. Abstr., 13, 707-730, https://doi.org/10.1016/0011-7471(66) 90602-4. $</$ jr $>$

Munk, W., and C. Wunsch, 1998: Abyssal recipes II: Energetics of tidal and wind mixing. Deep-Sea Res. I, 45, 1977-2010, https:// doi.org/10.1016/S0967-0637(98)00070-3.

Murray, R. J., 1996: Explicit generation of orthogonal grids for ocean models. J. Comput. Phys., 126, 251-273, https://doi.org/ 10.1006/jcph.1996.0136.

Nurser, A. G., and M.-M. Lee, 2004: Isopycnal averaging at constant height. Part II: Relating to the residual streamfunction in Eulerian space. J. Phys. Oceanogr., 34, 2740-2755, https:// doi.org/10.1175/JPO2650.1.

Nycander, J., J. Nilsson, K. Döös, and G. Broström, 2007: Thermodynamic analysis of ocean circulation. J. Phys. Oceanogr., 37, 2038-2052, https://doi.org/10.1175/JPO3113.1.

Otto, A., and Coauthors, 2013: Energy budget constraints on climate response. Nat. Geosci., 6, 415-416, https://doi.org/ $10.1038 /$ ngeo1836.

Raper, S. C., J. M. Gregory, and R. J. Stouffer, 2002: The role of climate sensitivity and ocean heat uptake on AOGCM transient temperature response. J. Climate, 15, 124-130, https://doi.org/ 10.1175/1520-0442(2002)015<0124:TROCSA > 2.0.CO;2.

Redi, M. H., 1982: Oceanic isopycnal mixing by coordinate rotation. J. Phys. Oceanogr., 12, 1154-1158, https://doi.org/ 10.1175/1520-0485(1982)012<1154:OIMBCR>2.0.CO;2.

Rhein, M., and Coauthors, 2013: Observations: Ocean. Climate Change 2013: The Physical Science Basis, T. F. Stocker et al., Eds., Cambridge University Press, 255-316, https://doi.org/ 10.1017/CBO9781107415324.010.

Saenko, O. A., 2009: On the climatic impact of wind stress. J. Phys. Oceanogr., 39, 89-106, https://doi.org/10.1175/2008JPO3981.1.

Snow, K., A. M. Hogg, S. M. Downes, B. M. Sloyan, M. L. Bates, and S. M. Griffies, 2015: Sensitivity of abyssal water masses 
to overflow parameterisations. Ocean Modell., 89, 84-103, https://doi.org/10.1016/j.ocemod.2015.03.004.

Sohail, T., C. A. Vreugdenhil, B. Gayen, and A. M. Hogg, 2019: The impact of turbulence and convection on transport in the Southern Ocean. J. Geophys. Res. Oceans, 124, 4208-4221, https:// doi.org/10.1029/2018JC014883.

Solomon, H., 1971: On the representation of isentropic mixing in ocean circulation models. J. Phys. Oceanogr., 1, 233-234, https://doi.org/10.1175/1520-0485(1971)001<0233:OTROIM> 2.0.CO;2.

Stewart, K., A. M. Hogg, S. Griffies, A. Heerdegen, M. Ward, P. Spence, and M. England, 2017: Vertical resolution of baroclinic modes in global ocean models. Ocean Modell., 113, 50-65, https://doi.org/10.1016/j.ocemod.2017.03.012.

—_, and Coauthors, 2020: JRA55-do-based repeat year forcing datasets for driving ocean-sea-ice models. Ocean Modell., 147, 101557, https://doi.org/10.1016/j.ocemod.2019.101557.

Stommel, H., and A. B. Arons, 1960: On the abyssal circulation of the world ocean-II. An idealized model of the circulation pattern and amplitude in oceanic basins. Deep-Sea Res., 6, 217-233, https://doi.org/10.1016/0146-6313(59)90075-9.

Sweeney, C., A. Gnanadesikan, S. M. Griffies, M. J. Harrison, A. J. Rosati, and B. L. Samuels, 2005: Impacts of shortwave penetration depth on large-scale ocean circulation and heat transport. J. Phys. Oceanogr., 35, 1103-1119, https://doi.org/ 10.1175/JPO2740.1.

Todd, A., and Coauthors, 2020: Ocean-only FAFMIP: Understanding regional patterns of ocean heat content and dynamic sea level change. J. Adv. Model. Earth Syst., 12, e2019MS002027, https:// doi.org/10.1029/2019MS002027.

Tsujino, H., and Coauthors, 2018: JRA-55 based surface dataset for driving ocean-sea-ice models (JRA55-do). Ocean Modell., 130, 79-139, https://doi.org/10.1016/j.ocemod.2018.07.002.
Valcke, S., 2006: OASIS user guide, PRISM 2-5. PRISM-Support Initiative Rep. 3, 68 pp., http://www.prism.enes.org/Publications/ Reports/oasis3_UserGuide_T3.pdf.

von Schuckmann, K., and Coauthors, 2020: Heat stored in the Earth system: Where does the energy go? Earth Syst. Sci. Data, 12, 2013-2041, https://doi.org/10.5194/essd-12-2013-2020.

Waterhouse, A. F., and Coauthors, 2014: Global patterns of diapycnal mixing from measurements of the turbulent dissipation rate. J. Phys. Oceanogr., 44, 1854-1872, https:// doi.org/10.1175/JPO-D-13-0104.1.

WCRP Global Sea Level Budget Group, 2018: Global sea-level budget 1993-present. Earth Syst. Sci. Data, 10, 1551-1590, https://doi.org/10.5194/essd-2018-53.

Wolfe, C. L., P. Cessi, J. L. McClean, and M. E. Maltrud, 2008: Vertical heat transport in eddying ocean models. Geophys. Res. Lett., 35, L23605, https://doi.org/10.1029/2008GL036138.

Zhang, Z., B. Qiu, P. Klein, and S. Travis, 2019: The influence of geostrophic strain on oceanic ageostrophic motion and surface chlorophyll. Nat. Commun., 10, 2838, https://doi.org/10.1038/ s41467-019-10883-w.

Zika, J. D., W. P. Sijp, and M. H. England, 2013a: Vertical heat transport by ocean circulation and the role of mechanical and haline forcing. J. Phys. Oceanogr., 43, 2095-2112, https:// doi.org/10.1175/JPO-D-12-0179.1.

— Ocean. J. Phys. Oceanogr., 43, 941-955, https://doi.org/ 10.1175/JPO-D-12-0178.1.

—, F. Laliberté, L. R. Mudryk, W. P. Sijp, and A. Nurser, 2015: Changes in ocean vertical heat transport with global warming. Geophys. Res. Lett., 42, 4940-4948, https://doi.org/10.1002/ 2015 GL064156.

Zweng, M. M., and Coauthors, 2013: Salinity. Vol. 2, World Ocean Atlas 2013, NOAA Atlas NESDIS 74, 39 pp. 